Repository of the Max Delbrück Center for Molecular Medicine (MDC) Berlin (Germany)

\title{
Identification of LRRC8 heteromers as an essential component of the volume-regulated anion channel VRAC.
}

Voss, F.K., Ullrich, F., Muench, J., Lazarow, K., Lutter, D., Mah, N., Andrade-Navarro, M.A., von Kries, J.P., Stauber, T., Jentsch, T.J.

This is the author's version of the work. It is posted here by permission of the AAAS for personal use, not for redistribution. The definitive version was published in Science on 2014 May 9 ; 344 (6184): 634-638, DOI: http://dx.doi.org/10.1126/science.1252826 American Association for the Advancement of Science (AAAS) (U.S.A.) 
Title:

\title{
Identification of LRRC8 Heteromers as Essential Component of the Volume-regulated Anion Channel VRAC
}

\author{
Authors: \\ Felizia K. Voss ${ }^{1,2,3}$, Florian Ullrich ${ }^{1,2,3}$, Jonas Münch ${ }^{1,2,3}$, Katina Lazarow ${ }^{1}$, Darius Lutter ${ }^{1,2,3}$, \\ Nancy Mah², Miguel A. Andrade-Navarro², Jens P. von Kries ${ }^{1}$, Tobias Stauber ${ }^{1,2 *}$ and \\ Thomas J. Jentsch ${ }^{1,2,4}$ *
}

\begin{abstract}
Affiliations:
${ }^{1}$ Leibniz-Institut für Molekulare Pharmakologie (FMP), Berlin

${ }^{2}$ Max-Delbrück-Centrum für Molekulare Medizin (MDC), Berlin

${ }^{3}$ Graduate program of the Freie Universität Berlin

${ }^{4}$ Neurocure, Charité Universitätsmedizin, Berlin

*Correspondence to: Jentsch@fmp-berlin.de (T.J.J.); tstauber@fmp-berlin.de (T.S.).
\end{abstract}




\begin{abstract}
:
Regulation of cell volume is critical for many cellular and organismal functions, yet the molecular identity of a key player, the volume-regulated anion channel VRAC, has remained unknown. A genome-wide siRNA screen in mammalian cells identified LRRC8A as a VRAC component. LRRC8A formed heteromers with other LRRC8 multispan membrane proteins. Genomic disruption of $\angle R R C 8 A$ ablated VRAC currents. Cells with disruption of all five $L R R C 8$ genes required LRRC8A co-transfection with other LRRC8 isoforms to reconstitute VRAC currents. The isoform combination determined VRAC inactivation kinetics. Taurine flux and regulatory volume decrease also depended on LRRC8 proteins. Our work shows that VRAC defines a class of anion channels, suggests that VRAC is identical to the volumesensitive organic osmolyte/anion channel VSOAC, and explains the heterogeneity of native VRAC currents.
\end{abstract}

\title{
One Sentence Summary:
}

We show that the swelling-activated anion channel VRAC represents a structurally new class of anion channels that also conducts organic osmolytes.

\section{Main Text:}

Cells regulate their volume to counteract swelling or shrinkage caused by osmotic challenges and during processes like cell growth, division, and migration. As water transport across cellular membranes is driven by osmotic gradients, cell volume regulation requires appropriate changes of intracellular concentrations of ions or organic osmolytes like taurine $(1,2)$. Regulatory volume decrease (RVD) follows the extrusion of intracellular $\mathrm{Cl}^{-}$and $\mathrm{K}^{+}$and other osmolytes across the plasma membrane. A key player is the volume-regulated anion channel VRAC that mediates characteristic swelling-activated $\mathrm{Cl}^{-}$-currents $\left(\mathrm{I}_{\mathrm{Cl}(\text { swell)}}\right)$ and is ubiquitously expressed in vertebrate cells (3-5). Nearly inactive under resting conditions, VRAC slowly opens upon hypotonic swelling. The mechanism behind VRAC opening remains enigmatic. VRAC currents are outwardly rectifying (hence the alternative name VSOR for volume-stimulated outward rectifier $(4,5))$ and show variable inactivation at insidepositive voltages. VRAC conducts iodide better than chloride and might also conduct organic osmolytes like taurine (6) (hence VSOAC, volume-știmulated organic ossmolyte/annion channel (7)), but this notion is controversial (8-10). VRAC is believed to be important for cell volume regulation and swelling-induced exocytosis (11), and also for cell cycle regulation, proliferation and migration $(1,3,4)$. It may play a role in apoptosis and various pathological 
states including ischemic brain edema and cancer $(4,12)$. Progress in the characterization of VRAC and its biological roles has been limited by the failure to identify the underlying protein(s) despite efforts for decades $(1,5)$. ClC-2 $\mathrm{Cl}^{-}$-channels activate upon cell swelling, but their inward rectification and $\mathrm{Cl}^{-}$over $\mathrm{I}^{-}$selectivity deviate from VRAC (13) Drosophila dBest1, a member of a family of $\mathrm{Ca}^{2+}$-activated $\mathrm{Cl}^{-}$-channels, mediates swelling-activated $\mathrm{Cl}^{-}$currents in insect cells $(14,15)$, but their characteristics differ from VRAC currents and the mammalian homolog of dBest1 is swelling-insensitive (16). We show that VRAC represents a distinct class of anion channels that also conduct organic osmolytes.

To identify VRAC, we opted for a genome-wide RNA interference screen that could identify non-redundant VRAC components. Swelling-induced iodide influx into HEK cells expressing the iodide-sensitive yellow fluorescent protein YFP(H148Q//152L) (17) was used as read-out in a fluorometric imaging plate reader (Fig. 1A). Exposure to saline containing $50 \mathrm{mM}$ iodide entailed a slow fluorescence decay under isotonic conditions, whereas hypotonicity induced a delayed increase in YFP quenching (Fig. 1B) that could be reduced by VRAC inhibitors like carbenoxolone (18) (fig. S1). In a prescreen targeting 21 anion transporters (table S1), only siRNAs against the $\mathrm{Cl}^{-} / \mathrm{HCO}_{3}{ }^{-}$exchanger AE2 gave significant effects (Fig. 1B). They decreased iodide influx under both isotonic and hypotonic conditions.

Our genome-wide screen utilized three separately transfected siRNAs per gene (fig. S2). Offline data analysis (fig. S3, A and B) yielded the maximal slope of fluorescence quenching that was used to define hits. Further criteria included the presence of predicted transmembrane domains and a wide expression pattern. 87 genes (table S2) were taken into a secondary screen with independent siRNAs. Of these, only suppression of LRRC8A robustly slowed hypotonicity-induced YFP quenching (Fig. 1C). LRRC8A knock-down also strongly suppressed $\mathrm{I}_{\mathrm{Cl}(\text { swell) }}$ in patch-clamp experiments (Fig. 1, D to $\mathrm{F}$ ), suggesting that the multispan membrane protein LRRC8A is an indispensable component of VRAC or is needed for its activation.

Although LRRC8A reached the plasma membrane (fig. S4A for HeLa cells), its transfection into HEK cells rather decreased $\mathrm{I}_{\mathrm{Cl}(\text { swell) }}(\mathrm{Fig} .1 \mathrm{~F})$. We hypothesized that VRAC contains LRRC8A as part of a heteromer and that LRRC8A overexpression led to a subunit stoichiometry that was incompatible with channel activity. LRRC8A has four closely related homologs (LRRC8B - LRRC8E) which all have four predicted transmembrane domains (19, 20). EST databases suggested that all homologs were widely expressed. Immunocytochemistry of transfected HeLa cells (fig. S4A) and of native HEK cells (Fig. 1, G and $\mathrm{H}$ ) detected LRRC8A at the plasma membrane. Truncation of its carboxy-terminus as in a patient with agammaglobulinemia (21) led to cytoplasmic retention (fig. S4B). LRRC8B through LRRC8E remained intracellular when transfected alone, but reached the plasma membrane when co-transfected with LRRC8A (Fig. 1, I and J, fig. S4, C to H). Unlike 
LRRC8A transfection, LRRC8A/LRRC8C co-expression did not suppress $I_{C /(s w e l l)}$ (Fig. 1F). However, neither this co-expression, nor any other combination tested, significantly increased current amplitudes above WT levels.

We used zinc-finger nuclease and CRISPR/Cas (22) technologies to constitutively disrupt LRRC8 genes. Besides polyploid HEK cells we used stably diploid human HCT116 cells for increased disruption efficiency. Gene disruption was confirmed by sequencing and Western blots (Fig. 2A, table S3). To exclude off-target effects, we generated two HEK and three HCT116 lines in which LRRC8A was disrupted at different positions (tables S3 and S4). $\mathrm{I}_{\mathrm{Cl}(\text { swell) }}$ was abolished in all five lines and could be rescued by LRRC8A transfection (Fig. 2, B and $\mathrm{C}$, and fig. S5), proving that LRRC8A is essential for $\mathrm{I}_{\mathrm{Cl}(\text { swell). }}$. We also produced HCT116 cells in which other $L R R C 8$ genes were disrupted singly or in combinations, including a line with disruption of all five $L R R C 8$ genes (henceforth called $L R R C 8^{-/}$cells). Except for $\angle R R C 8 A$, disruption of single $L R R C 8$ genes did not abolish VRAC currents (Fig. 2, B and C). However, $I_{C \mid(s w e l l)}$ amplitudes were robustly reduced in $L R R C 8 E^{-/-}$and in $L R R C 8(C / E)^{-/-}$double and $L R R C 8(C / D / E)^{-1-}$ triple knock-out $(\mathrm{KO})$ cells. $I_{\mathrm{Cl}(\text { swell) }}$ was abolished in $L R R C 8(B / C / D / E)^{-1-}$ cells (Fig. 2, B and $\mathrm{C}$ ). $\mathrm{I}_{\mathrm{Cl}(\text { swell) }}$ inactivated faster and at less positive potentials in $L R R C 8 C^{-/-}$and $L R R C 8(C / E)^{-/-}$cells compared to wild-type (WT) HCT116, LRRC8B ${ }^{-/-}$, $L R R C 8 D^{-/-}$or $L R R C 8 E^{-1-}$ cells. By contrast, $I_{\mathrm{Cl}(\text { swell) }}$ inactivated more slowly and at more positive voltages in $L R R C 8(D / E)^{-/-} \mathrm{HTC}_{116}$ cells (Fig. 2, B and D, and fig. S6D) and in WT HEK cells (Fig. 1E). $\mathrm{I}_{\mathrm{Cl}(\text { swell) }}$ of these mutant cell lines retained the characteristic $\mathrm{I}^{-}>\mathrm{NO}_{3}>\mathrm{Cl}^{-}$ >>gluconate permeability sequence (fig S6A).

LRRC8A transfection into quintuple $\mathrm{KO} L R R C 8^{-/-}$cells failed to rescue $\mathrm{I}_{\mathrm{Cl}(\text { swell) }}$ (Fig. 2, $\mathrm{E}$ and $\mathrm{F}$ ), agreeing with the absence of $\mathrm{I}_{\mathrm{Cl}(\text { swell) }}$ in $L R R C 8(B / C / D / E)^{-/-}$cells (Fig. 2, B and C). Cotransfecting $L R R C 8^{-/-}$cells with LRRC8A and either LRRC8C or LRRC8E yielded $\mathrm{I}_{\mathrm{CI}(\text { swell) }}$ with current densities similar to native cells (Fig. 2F). Co-expressing LRRC8A with LRRC8D yielded lower currents (Fig. 2, E and F). No current was observed upon LRRC8A+B coexpression, which may relate to the poor expressibility of LRRC8B (Fig. 3, D and F). These findings fit to the low currents of $L R R C 8(C / E)^{-1-}$ cells (Fig. $2 \mathrm{C}$ ) where LRRC8A can only interact with poorly expressible LRRC8B and/or LRRC8D. Reconstituted $\mathrm{I}_{\mathrm{Cl}(\text { swell) }}$ activated like WT VRAC upon swelling (Fig. 2E) and displayed its typical anion permeability sequence (fig. S6, B and C).

$\mathrm{I}_{\mathrm{Cl}(\text { swell) }}$ inactivated more slowly and at more positive voltages when LRRC8A was coexpressed with LRRC8C in $L R R C 8^{-/}$cells compared to cells co-expressing LRRC8A with LRRC8E or LRRC8D (Fig. 2, E and G, and fig. S6E). This observation agreed with the faster $\mathrm{I}_{\mathrm{Cl}(\text { swell) }}$ inactivation in $L R R C 8 C^{-/}$cells (Fig. 2, B and D, and fig. S6D) in which the 'decelerating' LRRC8C subunit may be replaced by LRRC8E or other 'accelerating' subunits. 
Native $\mathrm{I}_{\mathrm{Cl}(\text { swell) }}$ currents display different inactivation kinetics (3). Whereas $\mathrm{I}_{\mathrm{Cl}(\text { swell) }}$ shows prominent inactivation at positive potentials in $\operatorname{HEK}(23,24)$ (Fig. 1E, Fig. 2D, and fig. S6D) and even more so in HCT116 cells (Fig. 2, B and D, and fig. S6D), it inactivates much less in blood cells like promyelocytic HL-60 cells, and in vascular smooth muscle and neurons (2426). EST databases suggest that these cells express the 'decelerating' subunit LRRC8C, but lack LRRC8E that potently induces inactivation (Fig. 2, E and G, and fig. S6E). Quantitative RT-PCR confirmed that HEK and HCT116 cells expressed LRRC8A through LRRC8E, whereas LRRC8E was almost absent from HL-60 cells (fig. S7). Moreover, HCT116 cells, whose $\mathrm{I}_{\mathrm{Cl}(\text { swell) }}$ inactivates more than that of HEK cells (Fig. 1E, Fig. 2, B and D, and fig. S6D), express less 'decelerating' LRRC8C than HEK (fig. S7).

LRRC8 proteins have four predicted transmembrane domains (TMDs) followed by hydrophilic C-termini with up to 17 leucine-rich repeats (27) (hence LRRC8 = leucine-rich repeat containing 8) (Fig. 3A). Their C-termini were originally thought to be extracellular (19, 21), but proteome databases revealed (20) that the TMD2-TMD3 linker can be phosphorylated and suggested that LRRC8 $\mathrm{N}$ - and C-termini are cytoplasmic (Fig. 3A). LRRC8 proteins display weak homology (20) to pannexins, pore-forming proteins (28) with connexin-like topology. Connexins form hexameric hemichannels and gap junctions (29). This similarity suggested (20) that LRRC8 proteins form hexameric channels for so far unknown substrates. Just like VRAC currents $(14,15,30)$, LRRC8 proteins are found in vertebrates, but not in other phyla like arthropoda (20).

We ascertained the pannexin- and connexin-like transmembrane topology of LRRC8A. Mutating potential N-linked glycosylation sites between TMD1 and TMD2 abolished the size shift upon PNGaseF treatment (Fig. 3B), demonstrating that this loop is extracellular. Immunofluorescence of cells transfected with HA-tagged LRRC8A constructs showed that the TMD3-4 segment is extracellular and the C-terminus cytoplasmic (Fig. 3C).

The formation of LRRC8 heteromers was confirmed by co-immunoprecipitation from HEK cells transfected with LRRC8A and epitope-tagged versions of either LRRC8B, C, D, or E. LRRC8A co-precipitated each of the other isoforms, but not the $\mathrm{Cl}^{-}$-channel $\mathrm{CIC}-1$ used as control (Fig. 3, D and E). Conversely, precipitation of epitope-tagged versions of LRRC8B through LRRC8E brought down LRRC8A (Fig. 3F). Co-precipitation of LRRC8 isoforms was also observed for native HEK cells (fig. S8).

Hypotonicity induced a robust taurine efflux from HEK and HCT116 cell lines, but not from their $L R R C 8 A^{-/-}$derivates (Fig. $4 \mathrm{~A}$ and fig. S9A) where it could be rescued by LRRC8A/LRRC8C co-transfection (fig. S9B for HEK). Taurine efflux was also abolished in LRRC8(B/C/D/E) $)^{-/-} \mathrm{HCT} 116$ cells (Fig. 4A). Since both $\mathrm{I}_{\mathrm{Cl} \text { (swell) }}$ and swelling-induced taurine efflux similarly depended on LRRC8 heteromers, VRAC is most likely identical to VSOAC, the volume-stimulated organic osmolyte/anion channel (7). Accordingly, $L R R C 8 A^{-/-} \mathrm{HEK}$ cells 
showed severely impaired volume regulation. After initial swelling, WT, but not $L R C C 8 A^{-/-}$ cells slowly reduced their cell volume in the continuous presence of extracellular hypotonicity (Fig. 4B). Hence, LRRC8-containing VSOAC is a major player in RVD.

The identification of LRRC8 proteins as crucial VRAC constituents ends a decades-long hunt for the elusive molecular identity of this important channel. The absence of $\mathrm{I}_{\mathrm{Cl}(\text { swell) }}$ upon genomic disruption of $\angle R R C 8 A$ and its rescue by transient re-expression identified LRRC8A as an indispensable component of VRAC, or alternatively as being crucial for its activation. The wide expression pattern of LRRC8 genes and the plasma membrane residency of LRRC8A-containing heteromers are fulfilled prerequisites for LRRC8 proteins forming the channel. The dependence of current properties on LRRC8 isoform combinations indicated that LRRC8 heteromers are integral components of VRAC, a notion buttressed by the homology of LRRC8 proteins to pannexins. Since co-transfection of LRRC8 isoforms failed to significantly increase $\mathrm{I}_{\mathrm{Cl}(\text { swell) }}$ amplitude over WT levels other factors limit VRAC activity. Such a limiting component might be an auxiliary subunit of VRAC or could be part of the signaling cascade leading to its activation. Indeed VRAC currents seem to be highly regulated, with amplitudes differing only 2-3fold across cell types (3, 30).

The homology between LRRC8 proteins and pannexins suggested that LRRC8 proteins form hexameric channels (20). We confirmed the pannexin-like topology of LRRC8A and propose that VRAC is formed by LRRC8 hexamers of LRRC8A and minimally one other family member. In this model, VRAC may contain two to five different LRRC8 isoforms. This could create a large variety of VRAC channels with different properties. The variation of $\mathrm{I}_{\mathrm{Cl}(\text { swell) }}$ inactivation kinetics between different tissues and cells (3) can now be ascribed to different expression ratios of LRRC8 isoforms. LRRC8-dependent $\mathrm{Cl}^{-}$- and taurine-fluxes indicated that VRAC is identical to VSOAC (6) and fit to a pore formed by LRRC8 hexamers because hexameric pannexin channels likewise display poor substrate specificity (28).

Our work provides the basis to explore the structure-function relationship of VRAC/VSOAC, to clarify the signal transduction from cell volume increase to channel opening, and to investigate the role of the channel in basic cellular processes like cell division, growth, and migration and in various pathological states. Interestingly, a truncating $\angle R R C 8 A$ mutation has been described in a patient with agammaglobulinemia (21) and $L R R C 8 C$ may have a role in fat metabolism (31). 


\section{References and Notes:}

1. E. K. Hoffmann, I. H. Lambert, S. F. Pedersen, Physiol Rev 89, 193 (2009).

2. H. Pasantes-Morales, R. A. Lezama, G. Ramos-Mandujano, K. L. Tuz, The American journal of medicine 119, S4 (2006).

3. B. Nilius et al., Prog Biophys Mol Biol 68, 69 (1997).

4. Y. Okada, K. Sato, T. Numata, J Physiol 587, 2141 (2009).

5. Y. Okada, Am J Physiol 273, C755 (1997).

6. $\quad$ P. S. Jackson, K. Strange, Am J Physiol 265, C1489 (1993).

7. K. Strange, P. S. Jackson, Kidney Int 48, 994 (1995).

8. I. H. Lambert, E. K. Hoffmann, J Membr Biol 142, 289 (1994).

9. D. B. Shennan, Cell Physiol Biochem 21, 15 (2008).

10. A. Stutzin et al., Am J Physiol 277, C392 (1999).

11. T. Moser, R. H. Chow, E. Neher, Pflügers Arch 431, 196 (1995).

12. Y. Okada et al., J Membr Biol 209, 21 (2006).

13. S. Gründer, A. Thiemann, M. Pusch, T. J. Jentsch, Nature 360, 759 (1992).

14. S. C. Stotz, D. E. Clapham, PLoS ONE 7, e46865 (2012).

15. L. T. Chien, H. C. Hartzell, J Gen Physiol 132, 537 (2008).

16. R. Fischmeister, H. C. Hartzell, J Physiol 562, 477 (2005).

17. L. J. Galietta, P. M. Haggie, A. S. Verkman, FEBS Lett 499, 220 (2001).

18. V. Benfenati et al., Channels 3, 323 (2009).

19. K. Kubota et al., FEBS Lett 564, 147 (2004).

20. F. Abascal, R. Zardoya, Bioessays 34, 551 (2012).

21. A. Sawada et al., J Clin Invest 112, 1707 (2003).

22. L. Cong et al., Science 339, 819 (2013).

23. B. Nilius, J. Prenen, U. Wissenbach, M. Bodding, G. Droogmans, Pflügers Arch 443, 227 (2001).

24. C. Y. Hernández-Carballo, J. A. De Santiago-Castillo, T. Rosales-Saavedra, P. Pérez-Cornejo, J. Arreola, Pflügers Arch 460, 633 (2010).

25. G. X. Wang et al., Am J Physiol Heart Circ Physiol 287, H533 (2004).

26. J. L. Leaney, S. J. Marsh, D. A. Brown, J Physiol 501, 555 (1997).

27. G. Smits, A. V. Kajava, Molecular immunology 41, 561 (2004).

28. S. Penuela, R. Gehi, D. W. Laird, Biochim Biophys Acta 1828, 15 (2013).

29. S. Maeda et al., Nature 458, 597 (2009).

30. B. Nilius et al., Pflügers Arch 428, 364 (1994).

31. T. Hayashi et al., Biological \& pharmaceutical bulletin 34, 1257 (2011).

32. M. Magrane, U. Consortium, Database : the journal of biological databases and curation 2011, bar009 (2011).

33. T. J. Lopes et al., Bioinformatics 27, 2414 (2011).

34. A. Krogh, B. Larsson, G. von Heijne, E. L. Sonnhammer, J Mol Biol 305, 567 (2001).

35. P. Mali et al., Science 339, 823 (2013).

36. M. B. Rust et al., J Clin Invest 117, 1708 (2007).

37. S. Arvidsson, M. Kwasniewski, D. M. Riano-Pachon, B. Mueller-Roeber, BMC bioinformatics 9, 465 (2008).

38. J. E. Capó-Aponte, P. Iserovich, P. S. Reinach, J Membr Biol 207, 11 (2005).

\section{Acknowledgements:}

We thank Dr. M. Neuenschwander for technical advice concerning the assay, Dr. H.-P. Rahn for help with FACS-sorting, Drs. A. Brockhoff and W. Meyerhof for using their FLIPR ${ }^{\mathrm{TM}}$ in a pilot experiment, J. Liebold, N. Krönke, J. Jedamzick and S. Kleissle for technical assistance. Supported by the European Research Council (ERC) Advanced Grant (FP/2007-2013) 294435 'Cytovolion' and the DFG (Exc 257 'Neurocure') to TJJ. 
A
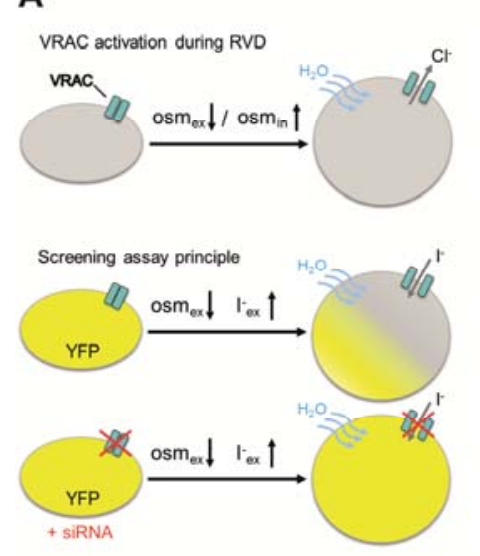

D
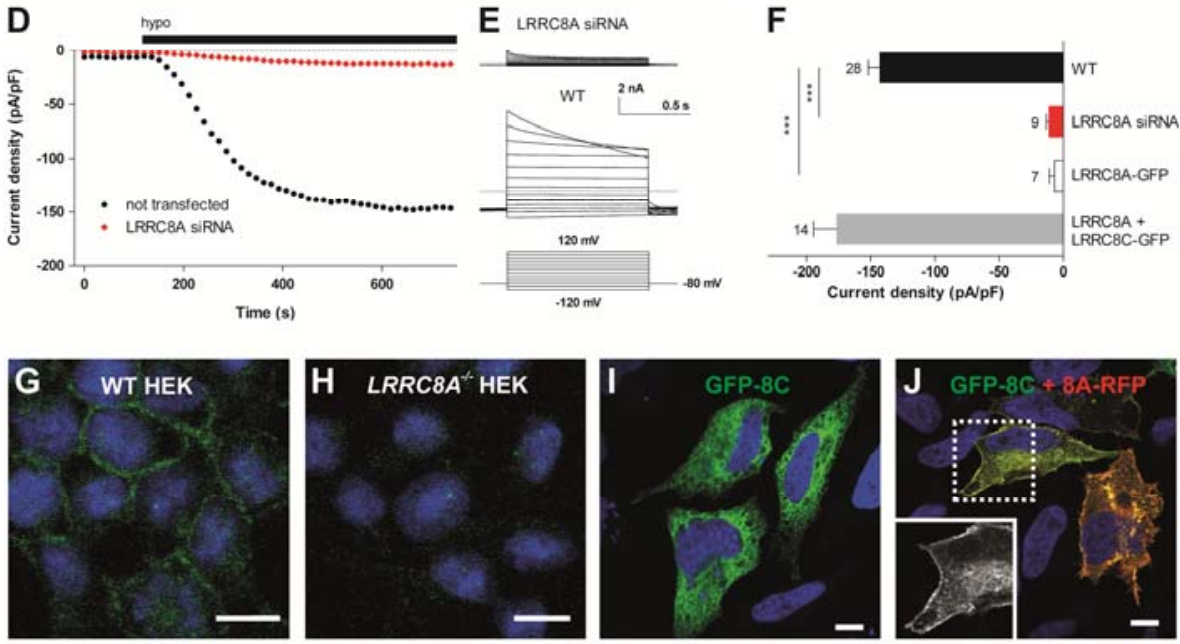

Fig. 1. siRNA screen for volume-regulated anion channel VRAC identifies LRRC8A.

(A) Principle of screen. Top, in regulatory volume decrease (RVD) VRAC releases chloride. Below, quenching of YFP fluorescence by iodide entering through VRAC used as read-out. (B) Example traces, normalized to fluorescence at $\sim 30-50 \mathrm{~s}$. Averaged from wells treated with control siRNAs (scrambled, AE2, both $n=3$ ) and no siRNA $(n=2)$ (error bars, SEM), and individual traces from wells singly transfected with the 3 siRNAs against LRRC8A. Except for LRRC8A siRNA2 and 3, all traces are from the same plate. Arrow indicates addition of iodide-containing hypotonic (hypo; $229 \mathrm{mOsm}$ ) or isotonic (iso; $329 \mathrm{mOsm}$ ) saline. (C) Secondary screen using siRNA pools against candidate genes. Averaged control traces as above. (D) Typical time course of VRAC activation in WT or LRRC8A siRNA-treated HEK cells. Current densities at $-80 \mathrm{mV}$ are shown. Bar, application of hypotonic (240 mOsm) saline (hypo). (E) Current traces of fully activated $\mathrm{I}_{\mathrm{Cl}(\text { swell) }}$ measured using the protocol shown below. Dotted lines indicate zero current. (F) $I_{\mathrm{Cl}(\text { swell) }}$ amplitudes (at $-80 \mathrm{mV}$ ) of WT HEK cells, cells treated with LRRC8A siRNA, or transfected with indicated LRRC8 cDNAs. Error bars, SEM; number of experiments is indicated; ${ }^{* *}, p<0.001$. (G) Plasma membrane localization of 
endogenous LRRC8A in HEK cells. (H) No LRRC8 labeling in LRRC8A $A^{-/-}$HEK cells. (I) LRRC8C is intracellular when transfected into HeLa cells, but $(\mathbf{J})$ reaches the plasma membrane when co-transfected with LRRC8A. Inset, magnification of boxed area showing only GFP-fluorescence. Scale bars, $10 \mu \mathrm{m}$.

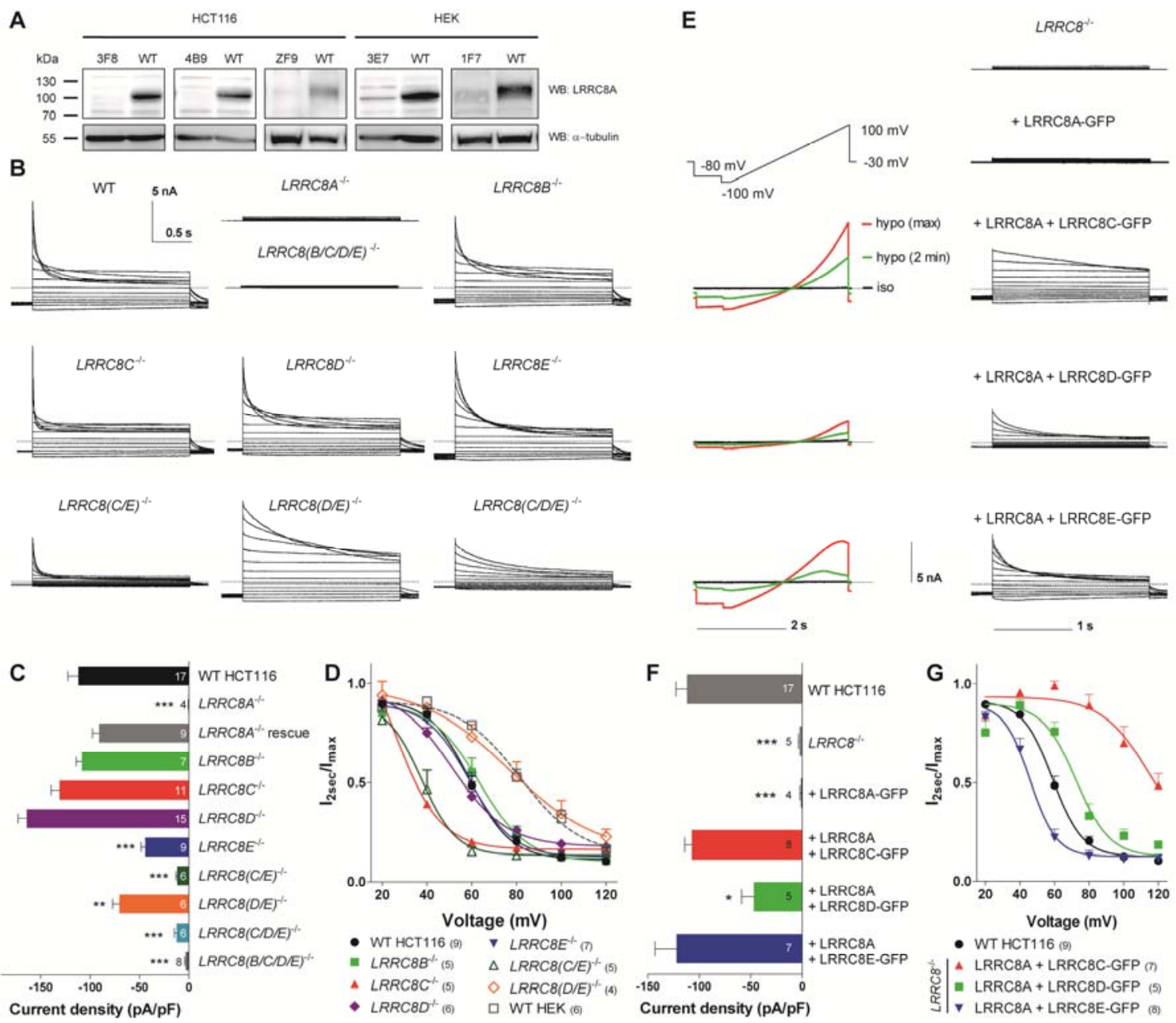

Fig. 2. Characterization of LRRC8 $\mathrm{KO}$ cells and of reconstituted $\mathrm{I}_{\mathrm{Cl}(\text { swell). }}(\mathrm{A})$ Western blots confirm $L R R C 8 A$ disruption in mutant cell lines (table S3). $\alpha$-tubulin, loading control. (B) Example $\mathrm{I}_{\mathrm{Cl}(\text { swell) }}$ traces (as in Fig. 1E, but 2-s pulses) of WT and mutant HCT116 cells. (C) Current densities (at $-80 \mathrm{mV}$ ) of maximally activated $\mathrm{I}_{\mathrm{Cl}(\text { swell) }}$ of WT and mutant HCT116 cells. (D) $\mathrm{I}_{\mathrm{Cl}(\text { swell) }}$ inactivation assessed by ratio of current at end/beginning of pulse. (E) When transfected into HCT116 LRRC8 ${ }^{-/}$cells (with all LRRC8 genes disrupted), LRRC8A rescues $\mathrm{I}_{\mathrm{Cl}(\text { swell) }}$ only with LRRC8C, D or E. Left, example ramp current traces from reconstituted $\mathrm{I}_{\mathrm{Cl}(\text { swell) }}$ at isotonicity (black), 2 minutes after switching to hypotonicity (green) and with maximal activation (red). (F) $\mathrm{I}_{\mathrm{Cl}(\text { swell) }}$ current densities at $-80 \mathrm{mV}$ for indicated combinations. (G) Voltage-dependent inactivation of $\mathrm{I}_{\mathrm{C}(\text { (swell) }}$. Error bars, SEM. Number of cells in brackets. *, $p<0.05^{* *}, p<0.01$ and ${ }^{* * *}, p<0.001$ vs. WT. 


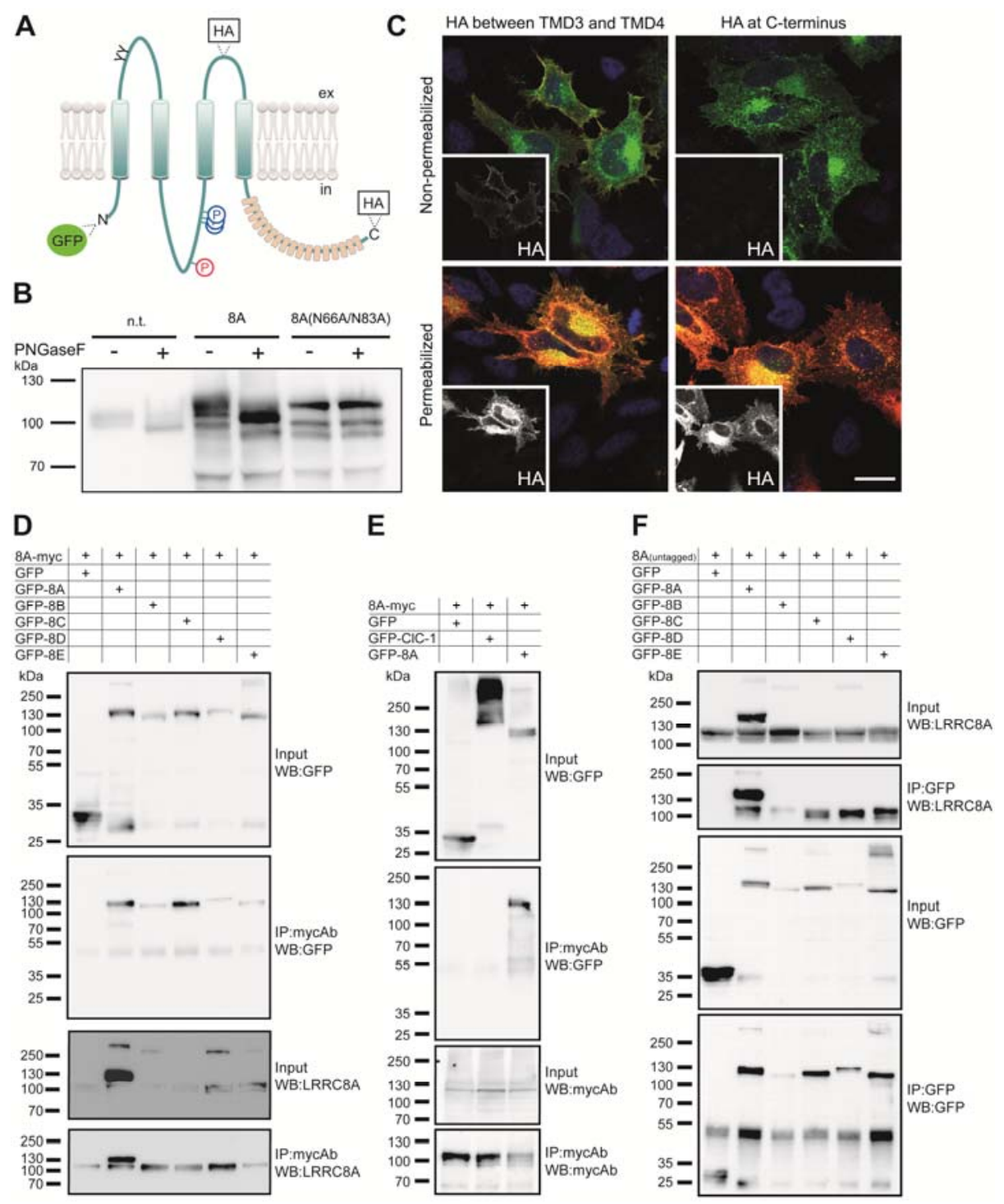

Fig. 3. Transmembrane topology and heteromerization of LRRC8A. (A) LRRC8 model (modified from (20)). Four transmembrane domains precede a C-terminus with up to 17 leucine-rich repeats (27) (orange). Phosphoserines in LRRC8A (red P) and LRRC8D (blue P) according to Uniprot (32), predicted $\mathrm{N}$-linked glycosylation sites $(\mathrm{Y})$ and added epitopes are indicated. (B) PNGaseF treatment of endogenous LRRC8A, transfected LRRC8A, but not of LRRC8A(N66A,N83A) with disrupted glycosylation sites, decreased LRRC8A size in Western blots. The changed banding pattern of LRRC8A(N66A,N83A) suggests altered posttranslational modifications. n.t., non-transfected. (C) Immunofluorescence of nonpermeabilized and permeabilized HeLa cells transfected with HA-tagged GFP-LRRC8A. Overlays of GFP (green) and HA (red) labeling. Insets show exclusively HA-staining. Scale bar, $20 \mu \mathrm{m}$. (D) LRRC8A co-precipitated epitope-tagged LRRC8B through LRRC8E in double-transfected HEK cells. LRRC8B and LRRC8D were poorly expressible. (E) LRRC8A 
did not co-precipitate the CIC-1 $\mathrm{Cl}^{-}$channel. (F) Epitope-tagged LRRC8B through LRRC8E co-precipitated LRRC8A.
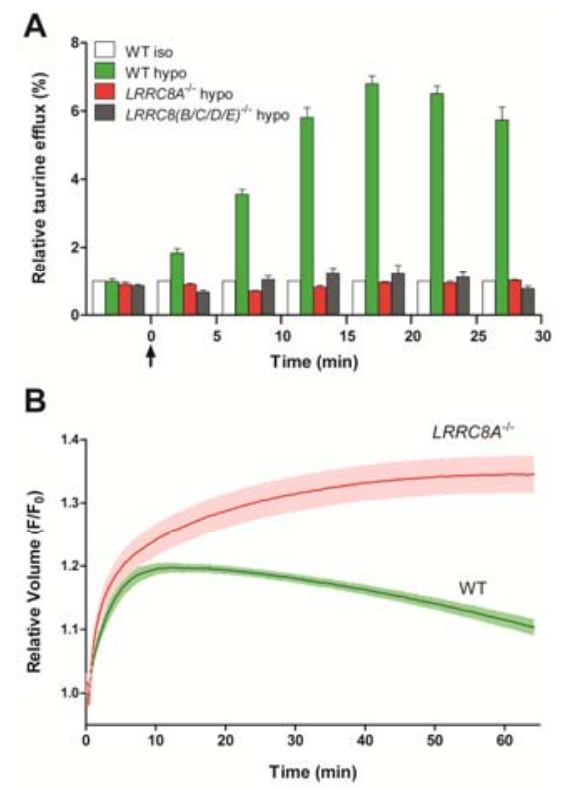

Fig. 4. LRRC8 proteins are crucial for swelling-induced taurine efflux and RVD. (A) ${ }^{3}[\mathrm{H}]$-taurine efflux from HCT116 cells of indicated genotypes. Cells were either in isotonic solution throughout (WT, white bars), or exposed to hypotonic solution starting at $\mathrm{t}=0$ (arrows). Bars, means of 6 measurements; error bars, SEM. (B) WT and LRRC8A $A^{-1-}$ HEK cells were shifted to hypotonic saline ( $96 \mathrm{mOsm})$ at $\mathrm{t}=30 \mathrm{~s}$ and cell volume was monitored by calcein fluorescence. Mean of 6 measurements; error range, SEM. Similar results obtained in 3 experiments.

\section{Supplementary Materials Contain:}

Materials and Methods

Author contributions

Figures S1-S10

Tables S1-S4

References 33-38 


\section{Supplementary Materials:}

Materials and Methods

Author contributions

Figures S1-S10

Tables S1-S4

References 33-38

\section{Materials and Methods}

\section{HEK293-YFP Cell Line Used in the siRNA Screen}

The T-REx® system (Life Technologies) was used to generate a stable HEK293 cell line inducibly expressing the halide-sensitive YFP(H148Q/I152L) (17). Clones were selected using $200 \mu \mathrm{g} / \mathrm{ml}$ hygromycin $\mathrm{B}$ and $10 \mu \mathrm{g} / \mathrm{ml}$ blasticidin. Monoclonal cell lines were subsequently tested for robust and homogenous expression of YFP after induction with 1.25 $\mu \mathrm{g} / \mathrm{ml}$ doxycycline using life-cell imaging. The clone 1:5-(6) was chosen for the genome-wide screening procedure. The cells were kept in DMEM with tetracycline-free Hyclone FCS (Thermo Scientific) and the above-mentioned antibiotics.

\section{Genome-wide siRNA Screen}

The screen was performed at the FMP Screening Unit using the Ambion Silencer ${ }^{\circledR}$ Human Genome siRNA Library V3 (Life Technologies) containing 189 384-well plates. This library targets each gene by three independently placed siRNAs. The screen was performed in two replicates. Each screening plate contained several controls like siRNA pools against YFP (Silencer GFP siRNA from Ambion), a non-targeting siRNA (Silencer Negative Control from Ambion), an siRNA pool against AE2 (ON-TARGETplus SMARTpool siRNA SLC4A2 from Thermo Scientific) and a cell death-inducing siRNA mixture (AllStars Hs Cell Death Control siRNA from Qiagen). For detailed plate layout see fig. S2. For siRNA transfection, in each well of the 384 -well assay-plate $8 \mu$ l of a $500 \mathrm{nM}$ library-siRNA-OptiMEM ${ }^{\circledR}$ solution was mixed with $0.2 \mu \mathrm{l}$ Lipofectamine ${ }^{\circledR}$ RNAimax transfection reagent (Life Technologies) previously diluted in $11.8 \mu \mathrm{l}$ Opti-MEM ${ }^{\circledR}$ (Life Technologies). Subsequently 6000 cells/well in antibioticfree DMEM were seeded onto the pre-dispensed transfection mixture using a BioTek EL406 ${ }^{\mathrm{TM}}$ dispenser resulting in a final concentration of $50 \mathrm{nM}$ siRNA in a total volume of $80 \mu \mathrm{l}$ per well. After $24 \mathrm{~h}$ the cell culture medium was exchanged to phenol red-free DMEM containing $1.25 \mu \mathrm{g} / \mathrm{ml}$ doxycycline to induce YFP-expression.

The YFP-quenching assay was performed $72 \mathrm{~h}$ post-transfection. After having exchanged the cell culture medium in all wells of the plate with $10 \mu \mathrm{l}$ of isotonic solution (in mM: $145 \mathrm{NaCl}, 5 \mathrm{KCl}, 1 \mathrm{MgCl}_{2}, 2 \mathrm{CaCl}_{2}, 10$ glucose, 10 HEPES pH 7.4, 329 mOsm) in a 
Tecan Freedom EVO 200 workstation, the plates were transferred into the FLIPR ${ }^{\mathrm{TM}}$ (Molecular Devices) High Throughput Cellular Screening Device and fluorescence measurements were initiated. All wells of the plate were simultaneously illuminated at $\lambda=$ 495-505 $\mathrm{nm}$ and YFP-fluorescence was measured at $\lambda=526-585 \mathrm{~nm}$ using the FLIPR Fluo3 LED/filter set. After 5 measurements in intervals of $5 \mathrm{~s}$, parallel pipetting within the FLIPR ${ }^{\mathrm{TM}}$ added $25 \mu$ iodide-containing hypotonic (rows 1-23) (in mM: $70 \mathrm{Nal}, 5 \mathrm{NaCl}, 5 \mathrm{KCl} ; 1 \mathrm{MgCl}_{2}$, $2 \mathrm{CaCl}_{2}, 10$ glucose, 10 HEPES pH 7.4, 189 mOsm) or isotonic (row 24) (in mM: $70 \mathrm{Nal}, 5$ $\mathrm{NaCl}, 5 \mathrm{KCl} ; 1 \mathrm{MgCl}_{2}, 2 \mathrm{CaCl}_{2}, 10$ glucose, 140 mannitol, 10 HEPES pH 7.4, 329 mOsm) solution into each well. The solution added to wells O23, P23, O24 and P24 was hypotonic and contained $1 \%$ Triton $\mathrm{X} 100$. The mixture of the pre-existing $10 \mu \mathrm{l}$ isotonic solution and the newly added $25 \mu$ l hypotonic solution resulted in a final osmolarity of $229 \mathrm{mOsm}$, i.e. a $\sim 30 \%$ decrease in osmolarity, and a final concentration of $50 \mathrm{mM}$ iodide. Fluorescence measurements were continued for $55 \mathrm{~s}$ in 5 -s intervals, followed by 8 measurements in 30 -s intervals to minimize bleaching, and finally 10 measurements in 1-s intervals. The total amount of measurement (500 s) was sufficient for YFP-quenching to nearly reach steady state. At time points $0 \mathrm{~s}$ and $5 \mathrm{~s}$ (before pipetting) and at 25, 30, 35, 40, 45, and $490 \mathrm{~s}$ (during/after pipetting) photographs of the entire plate were taken to allow post-hoc control of the integrity of the cell layers of each well. All original fluorescence traces were stored for reanalysis.

\section{Parameters Extracted from FLIPR ${ }^{\mathrm{TM}}$ Screen and Bioinformatics Analysis}

Several parameters were extracted from the primary data and used for subsequent data evaluation (fig. S3, A and B). The averaged fluorescence before the pipetting step, $\mathrm{F}^{\mathrm{abs}}{ }_{\text {ante, }}$ was obtained by averaging values from measurements 1-3 and was used to set a warning 'low cell' flag when its value was less than 0.8 times of mean $F^{\text {abs }}$ ante averaged over all experimental wells from the plate. After pipetting, the fluorescence acutely changed to new values that were more or less stable for about $30 \mathrm{~s}$ before swelling-induced quenching of YFP set in. We averaged fluorescence values from measurements 9 to 12 to obtain $F^{\text {abs }}$ start which was subsequently used for normalization. $\mathrm{F}_{\text {fin }}^{\mathrm{abs}}$ was defined as averaged fluorescence from the four last measurements and we set another warning flag if fluorescence had not reached quasi-steady-state at the end of the measurement. $F_{\text {fin }}^{\text {abs }}$ might be used for background subtraction. We preferred, however, to subtract $F_{B G ~ T X 100}$, the averaged (over the last $300 \mathrm{~s}$ ) fluorescence of the four control wells from the same plate that had been exposed to Triton X100 to maximally quench YFP fluorescence. The background-subtracted fluorescence value of each well was then normalized to the corresponding $F^{\text {abs }}$ start value to yield $F^{*}$ (fig. S3B).

siRNA-mediated knock-down of VRAC should reduce iodide current magnitude, but not necessarily the final intracellular iodide concentration (reflected in $\mathrm{F}_{\text {fin }}^{\mathrm{abs}}$ ). Although not 
being a linear function of iodide influx, the speed of YFP quenching after exposure to hypotonicity is the best indicator for the magnitude of VRAC currents. We therefore determined the slope of fluorescence change by linear regression of 11 points in a sliding window between 35 and $350 \mathrm{~s}$. The maximum of these slopes was defined as $\mathrm{S}_{\max }$. The intersection of the corresponding linear regression line with $\mathrm{F}^{*}=1$ defined $t_{\text {onset }}$ as a measure for the speed of response to the hypotonic challenge, a delay that might be changed e.g. by interfering with the signal transduction cascade leading to VRAC opening (fig. S3B). For each individual plate we then calculated the mean maximal slope $S_{\max }{ }^{\text {mean }}$ of all experimental wells and the corresponding standard deviation. $S_{\max }$ of each individual siRNA-treated well was expressed in terms of standard deviations to yield Z-scores, with e.g. $Z=2$ meaning that the slope is slower by two standard deviations compared to the average of the plate.

siRNAs leading to cell death or targeting YFP confirmed that results of none of the 384-well plates had to be discarded because of low transfection efficiency. Results were sorted by genes and listed individually for each of the three siRNAs (which generally were on different plates) the Z-score, $\mathrm{t}_{\text {onset }}, \mathrm{F}_{\text {ante, }}^{\mathrm{abs}} \mathrm{F}_{\text {fin }}^{\mathrm{abs}}$, the low-cell and the non-steady-state flags ( 1 or 0 ). It also listed the protein families associated with the gene products (as obtained from UniProtKB database (32)), the genes' tissue expression pattern (as determined by publicly available microarray data (33)) and predicted number of transmembrane domains that was calculated by the software TMHMM 2.0c (34). Comparison of the first and replicate screen showed that the effects of individual siRNAs on the respective Z-scores of $S_{\text {max }}$ correlated reasonably well and demonstrated the usefulness of our warning flags (fig. S3, C and D). To account for different efficiencies of siRNA knock-down with the three individual siRNAs against each gene, some of which may be ineffective or show off-target effects, we sorted our results according to the mean $Z$ obtained with the two 'best' siRNAs (giving the largest values of $Z$ ).

As expected, many of the hits could be ruled out by one or more criteria. For instance, siRNAs against several ribosomal proteins led to large Z-scores that were caused by poor cell growth or cell death as indicated by the 'low cell' flag. Large Z-scores that were not reproduced in the replicate screen could sometimes be eliminated by examining the photographs of the plates which showed dirt at the respective well that had caused high background fluorescence. As we were looking for the channel itself and not for proteins involved in the activation of VRAC, we limited our search to proteins having at least one predicted transmembrane domain. Many candidates could be eliminated by their wellestablished function or their inclusion in well-known gene families like olfactory receptors or other G-protein coupled receptors. However, as annotations are not always reliable and as proteins may serve more than one function, several candidates whose annotated function appeared to be incompatible with VRAC function but which otherwise seemed promising 
were earmarked for a secondary screen. As VRAC currents have been observed in every mammalian tissue that has been investigated, we excluded candidates that showed a narrow tissue distribution or very low expression levels as indicated by NCBI EST profile databases or the scientific literature, except when they belonged to a gene family whose overlapping expression pattern covered many tissues.

On the basis of these criteria 87 candidate genes (table S2) were selected for a secondary screen that used again the FLIPR ${ }^{\mathrm{TM}}$ assay with pools of four siRNAs (ONTARGETplus SMARTpool siRNA, Thermo Scientific) that were different from the ones used in the primary screen. Of these genes, only LRRC8A passed the test. The SMART pool directed against LRRC8A slowed hypotonicity-induced quenching of YFP fluorescence better than the SMART-pool against AE2 (Fig. 1C). It is interesting to note that LRRC8A was at the $222^{\text {nd }}$ position of hits sorted exclusively by the mean Z-score averaged across both screens from the 2 out of 3 siRNAs per gene that gave the best score. Only one of the three siRNAs against $L R R C 8 A$ gave a Z-score for maximal slope of $\sim 2$, the two others were below 1 (fig. S3E).

\section{Generation of Monoclonal Knock-out Cell Lines Using the CRISPR/Cas and Zinc-finger Nuclease Technologies}

For the disruption of $L R R C 8$ genes by the CRISPR/Cas system in cell culture, we used the px330 single plasmid system as described (22). The targeting sgRNA sequences were chosen using both the UCSC Genome Browser tool at www.genome-engineering.org and the sequence collection from (35) (for sequences, table S4). Target sgRNAs were cloned into the px330 vector and transfected into the described YFP expressing HEK293 clone or WT HCT116 cells in a 6-well format using $3 \mu \mathrm{l}$ of the Fugene HD transfection reagent and $900 \mathrm{ng}$ targeting vector(s) (up to 4) plus $100 \mathrm{ng}$ pEGFP-C1-vector. In HCT116 cells, the LRRC8A gene was additionally disrupted using custom-designed CompoZr ${ }^{\circledR}$ Knock-out Zinc-Finger Nucleases (Sigma). The zinc-finger nuclease (ZFN) pair encoded on two separate plasmids was transfected as the CRISPR/Cas constructs described above, using $500 \mathrm{ng}$ of each ZFNplasmid and $100 \mathrm{ng}$ of the pEGFP-C1 vector. 2-5 days post-transfection single GFP-positive cells were FACS-sorted into 96-well plates containing preconditioned DMEM (for HEK cells) or McCoy's 5A (for HCT116 cells) medium. In some cases, transfected cells were enriched by G418 selection before FACS sorting.

Monoclonal cell lines were raised and tested for sequence alterations using target-sitespecific PCR on genomic DNA followed by Sanger-sequencing and/or Western blot analysis to confirm the absence of the protein when specific antibodies were available. To generate multiple KOs of several genes, the respective plasmids were transfected together, or cell lines already carrying $L R R C 8$ gene disruptions were targeted again for other $L R R C 8$ genes. 


\section{Antibodies}

Polyclonal antibodies against LRRC8A were raised in rabbits against the peptide QRTKSRIEQGIVDRSE that was coupled to $\mathrm{KLH}$ through an N-terminally added cysteine. Its sequence corresponds to LRRC8A protein sequence between TMD2 and TMD3. Polyclonal antibodies against the C-terminus of LRRC8E were raised in rabbits against the peptide LYEGLPAEVREKMEEE that was also coupled with an N-terminally added cysteine to KLH. Sera were affinity-purified against the respective peptide and proved specific in Western blots (Fig. 2A and fig. S10, A and B) and-for LRRC8A-in immunofluorescence (Fig. 1, G and $\mathrm{H}$, and fig. $\mathrm{S10C}$ ). The rabbit anti-KCC1 antibody was described previously (36).

The following commercial primary antibodies were used: rabbit anti-myc (A-14, Santa Cruz Biotechnology), rabbit anti-GFP (A-11122, Life Technologies) for IP and chicken anti-GFP (1020, Aves Lab) for Western blot, mouse anti- $\alpha$-tubulin (DM1A, Sigma), mouse anti-HA (HA.11, Covance). Secondary antibodies were conjugated to AlexaFluor 488 or 546 (Molecular Probes) or to horseradish peroxidase (Jackson ImmunoResearch).

\section{Expression Constructs and Immunocytochemistry}

For expression of LRRC8A - E with GFP fused to their N-termini or C-termini, cDNA encoding the respective human protein (or only aa 1-719 for $L R R C 8 A_{\text {trunc }}$ ) was cloned with stop codon into pEGFP-C1 or without stop codon into pEGFP-N1, respectively. For expression of C-terminally RFP-tagged LRRC8A, the cDNA was cloned into pmRFP-N1. cDNA encoding human CIC-1 was in pEGFP-C1. For untagged (co-expression in electrophysiological experiments and LRRC8A antibody testing by Western blot) and Cterminally myc-tagged (deglycosylation experiment and co-immunoprecipitations upon heterologous expression) expression, cDNA encoding LRRC8A was cloned (with and without stop codon, respectively) into pcDNA3.1/myc-His(-)B (Invitrogen). HA-tags (at T307 or at the extreme C-terminus of $\mathrm{LRRC} 8 \mathrm{~A}$ ) and point mutations were introduced by PCR. All constructs were confirmed by sequencing the complete ORF.

For immunocytochemistry, cells were transfected (if indicated) with plasmid encoding the respective construct(s) using Fugene HD. 24-36 h after transfection, cells were fixed in pre-cooled methanol at $-20^{\circ} \mathrm{C}$ for 10 min (immunostaining with LRRC8A antibody), or in $2 \%$ (topology assay) or 4\% PFA in PBS for $15 \mathrm{~min}$ followed by a 5-min incubation with $30 \mathrm{mM}$ glycine in PBS at room temperature. Cells were incubated sequentially for $1 \mathrm{~h}$ each with primary and secondary antibodies (where applicable) in PBS containing $0.1 \%$ Triton X-100 (or without Triton X-100, for non-permeabilized cells) supplemented with 3\% BSA. Images were acquired with an LSM510 confocal microscope with a 63x, 1.4 NA oil-immersion lens (Zeiss). 


\section{Quantitative RT-PCR}

Total RNA was isolated from cell pellets using the RNeasy Mini Kit (Qiagen). We subjected $\sim 1 \mu \mathrm{g}$ of RNA to DNase I (amplification grade, Invitrogen) digestion and subsequently transcribed it into cDNA using random primers and Superscript II reverse transcriptase (Invitrogen). A 20- $\mu$ l qRT-PCR reaction was set up using the Power SYBR Green PCR Master Mix (Applied Biosystems) and $0.5 \mu \mathrm{M}$ of specific primers. Reactions were run in triplicates with a $60-\mathrm{s}$ elongation time at $60^{\circ} \mathrm{C}$. Amplification and melting curves were monitored using a StepOnePlus Real-Time PCR System and StepOne Software (Applied Biosystems). GAPDH was used as internal control and for $\Delta \Delta \mathrm{Ct}$ calculations. Primers were designed using the QuantPrime selection tool (37) to preferentially span exon-exon boundaries and to give products of $60-150 \mathrm{bp}$. The following primer pairs were used (5'-3'):

GAPDH: ACAGTCAGCCGCATCTTCTT and GTTAAAAGCAGCCCTGGTGA

LRRC8A: GGGTTGAACCATGATTCCGGTGAC and GAAGACGGCAATCATCAGCATGAC

LRRC8B: ACCTGGATGGCCCACAGGTAATAG and ATGCTGGTCAACTGGAACCTCTGC

LRRC8C: ACAAGCCATGAGCAGCGAC and GGAATCATGTTTCTCCGGGC

LRRC8D: ATGGAGGAGTGAAGTCTCCTGTCG and CTTCCGCAAGGGTAAACATTCCTG

LRRC8E: ACCGTGGCCATGCTCATGATTG and ATCTTGTCCTGTGTCACCTGGAG

\section{Electrophysiology}

HEK or HCT cells were plated onto gelatine-coated coverslips and transfected using Fugene HD (Promega) or Lipofectamine 2000 (Life Technologies) transfection reagents, respectively. One of the transfected LRRC8 isoforms was fused C-terminally to GFP. When LRRC8A was co-transfected with other LRRC8 isoforms only the latter carried GFP because plasma membrane fluorescence indicated co-expression with LRRC8A.

Whole-cell voltage-clamp experiments were performed in isotonic extracellular solution containing (in mM) $150 \mathrm{NaCl}, 6 \mathrm{KCl}, 1 \mathrm{MgCl}_{2}, 1.5 \mathrm{CaCl}_{2}, 10$ glucose, and $10 \mathrm{HEPES}, \mathrm{pH} 7.4$ with $\mathrm{NaOH}(320 \mathrm{mOsm})$. $\mathrm{I}_{\mathrm{Cl}(\text { swell) }}$ was elicited by perfusing the cells with hypotonic solution containing (in mM) $105 \mathrm{NaCl}, 6 \mathrm{CsCl}, 1 \mathrm{MgCl}_{2}, 1.5 \mathrm{CaCl}_{2}, 10$ glucose, $10 \mathrm{HEPES}$, pH 7.4 with $\mathrm{NaOH}$ (240 mOsm). For anion selectivity experiments, $\mathrm{NaCl}$ was replaced in this solution by an equimolar amount of $\mathrm{Nal}, \mathrm{NaNO}_{3}$, or Na-D-gluconate. The pipette solution contained (in mM) $40 \mathrm{CsCl}, 100$ Cs-methanesulfonate, $1 \mathrm{MgCl}_{2}, 1.9 \mathrm{CaCl}_{2}, 5 \mathrm{EGTA}, 4$ $\mathrm{Na}_{2} \mathrm{ATP}$, and 10 HEPES, pH 7.2 with $\mathrm{CsOH}$ (290 mOsm). Osmolarities of all solutions were assessed with an Osmomat 030 freezing point osmometer (Gonotec). All experiments were performed at constant temperature of $20-22^{\circ} \mathrm{C}$. Currents were recorded with an EPC-10 USB patch-clamp amplifier and PatchMaster software (HEKA Elektronik) or a MultiClamp 700B patch-clamp amplifier/Digidata 1440A digitizer and pClamp 10 software (Molecular Devices). Patch pipettes had a resistance of 1-3 M 2 . Series resistance was compensated by $80-90 \%$ to minimize voltage errors. Currents were sampled at $5 \mathrm{kHz}$ and low-pass filtered at 
$10 \mathrm{kHz}$. The holding potential was $-30 \mathrm{mV}$. Cells with a membrane resistance below $800 \mathrm{M} \Omega$ or series resistance above $10 \mathrm{M} \Omega$ were discarded. The standard protocol for measuring the time course of $I_{\mathrm{Cl}(\text { swell) }}$ activation, applied every $15 \mathrm{~s}$ after membrane rupture, consisted of a 0.6 -s step to $-80 \mathrm{mV}$ followed by a 2.6 -s ramp from -100 to $100 \mathrm{mV}$. The read-out for $I_{\mathrm{Cl}(\text { swell) }}$ was the steady-state whole-cell current at $-80 \mathrm{mV}$ normalized to the cell capacitance (current density) subtracted by the baseline current density at $-80 \mathrm{mV}$ before perfusion with hypotonic

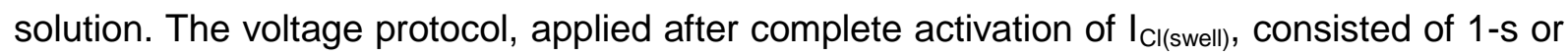
2-s steps starting from $-120 \mathrm{mV}$ to $120 \mathrm{mV}$ in $20-\mathrm{mV}$ intervals preceded and followed by a 0.5 -s step to $-80 \mathrm{mV}$ every $5 \mathrm{~s}$.

Relative anion permeabilities $\left(P_{\mathrm{X}} / P_{\mathrm{Cl}}\right)$ were calculated from the shifts in reversal potential induced by perfusion with the anion substituted hypotonic salines using a modified GoldmanHodgkin-Katz equation:

$$
P_{\mathrm{X}} / P_{\mathrm{Cl}}=\frac{[\mathrm{Cl}]_{\mathrm{hypo}} \exp \left(-\frac{\Delta E_{\text {rev }} F}{R T}\right)-[\mathrm{Cl}]_{\text {subst }}}{[\mathrm{X}]_{\text {subst }}}
$$

where $\Delta E_{\text {rev }}$ is the shift in reversal potential, $[\mathrm{Cl}]_{\text {hypo }}$ and $[\mathrm{Cl}]_{\text {subst }}$ are the extracellular chloride concentrations in the normal and anion substituted hypotonic saline, and $[X]_{\text {subst }}$ is the concentration of the substituting anion. $R$ is the gas constant, $T$ is the absolute temperature, and $F$ is the Faraday constant. Reversal potentials were determined by measuring 3 to 6 cells for each cell line or transfection. Liquid junction potentials were measured for all solutions and corrected for in ion selectivity experiments.

The inactivation kinetics of $\mathrm{I}_{\mathrm{Cl}(\text { swell) }}$ could not be fitted appropriately by a single-exponential function. We therefore calculated the fraction of remaining current by dividing the current amplitude at the end of the 2-s voltage step by the current amplitude $1.5 \mathrm{~ms}$ after the beginning of the voltage step (avoiding contamination by capacitive transients). The half inactivation time $t_{1 / 2}$ was determined by the time point where the inactivation reached half of the total inactivation after $2 \mathrm{~s}$. Calculation of current densities and inactivation characteristics was carried out with an automatic script written in MATLAB R2011a (MathWorks) and plotted with GraphPad Prism 5 (GraphPad Software). Boltzmann curve-fitting and calculation of $V_{1 / 2}$ was done with GraphPad Prism with the following fitting constraints: bottom value less than 0.2 , top value greater than 0.9 . Example current traces were lowpass-filtered at $2 \mathrm{kHz}$ and reduced to a sampling rate of $1 \mathrm{kHz}$ for clarity. Averaged data is presented as mean $\pm \mathrm{SEM}$. Significance was calculated by one-way ANOVA and Tukey's post-hoc test, where applicable. At least 4 cells per condition were measured on at least two different days; exact $\mathrm{n}$-values are given in the figures. Where possible, measurements were done blinded. 


\section{Deglycosylation, Co-immunoprecipitation and Western Blot}

To assess glycosylation of LRRC8A, HEK cells were transfected on 10-cm dishes using $17 \mu \mathrm{l}$ of polyethylenimine (PEI) and $6 \mu \mathrm{g}$ of plasmid encoding myc-tagged LRRC8A (wild-type or mutant). Cells were lysed in Ripa lysis buffer $(150 \mathrm{mM} \mathrm{NaCl}, 1 \% \mathrm{NP}-40,0.5 \%$ sodium deoxycholate, 0.1\% SDS, $50 \mathrm{mM}$ Tris, $\mathrm{pH}$ 8.0, $4 \mathrm{mM}$ Pefabloc (Roth), complete proteinase inhibitor cocktail (Roche)). After $10 \mathrm{~min}$ centrifugation at $14.000 \mathrm{rpm}$ at $4^{\circ} \mathrm{C}$, protein concentrations of cell lysates were determined by BCA assay. $60 \mu \mathrm{g}$ of total protein were mixed with $2 \mu \mathrm{l}$ of denaturing buffer (NEB) and $2 \mu \mathrm{l}$ of $0.1 \mathrm{M} \mathrm{Tris} / \mathrm{HCl} \mathrm{pH} 7.4$ in a reaction volume of $20 \mu \mathrm{l}$ and denatured at $75^{\circ} \mathrm{C}$ for $10 \mathrm{~min}$. Then $4 \mu \mathrm{l}$ of $10 \times \mathrm{xG}$ Buffer (NEB), $4 \mu \mathrm{l}$ of $10 \%$ NP-40 (NEB) and $4 \mu$ l of PNGase F (Roche) were added in a total volume of $40 \mu$ l. After $2 \mathrm{~h}$ incubation at $37^{\circ} \mathrm{C}$, the reaction was terminated by adding $10 \mu \mathrm{l}$ xLämmli sample buffer. Samples were separated by SDS-PAGE and analyzed by Western blot using the LRRC8A antibody. The experiment was repeated 3 times.

For co-immunoprecipitation, HEK cells were co-transfected with plasmids (6 $\mu \mathrm{g}$ total) encoding myc-tagged or untagged LRRC8A and N-terminal fusion constructs of LRRC8A-E or CIC-1 (or soluble GFP) on 10-cm dishes using PEI as described above. $48 \mathrm{~h}$ posttransfection cells were lysed in $300 \mu \mathrm{l}$ lysis buffer $(150 \mathrm{mM} \mathrm{NaCl}, 1 \% \mathrm{NP}-40,0.5 \%$ sodium deoxycholate, $50 \mathrm{mM}$ Tris- $\mathrm{HCl} \mathrm{pH}$ 7.5, $4 \mathrm{mM}$ Pefabloc (Roth), complete proteinase inhibitor cocktail (Roche)) for $10 \mathrm{~min}$ on ice. The lysate was pre-cleared by centrifugation at $14.000 \mathrm{rpm}$ for $10 \mathrm{~min}$ at $4^{\circ} \mathrm{C}$ and subsequently spun at $30.000 \mathrm{~g}$ for $30 \mathrm{~min}$ at $4^{\circ} \mathrm{C} .150 \mu \mathrm{l}$ of the supernatant were mixed with $10 \mu \mathrm{g}$ of the respective antibody and IP buffer $(150 \mathrm{mM}$ $\mathrm{NaCl}, 0.1 \%$ NP-40; $0.05 \%$ sodium deoxycholate, $50 \mathrm{mM}$ Tris- $\mathrm{HCl}, \mathrm{pH} 7.5$, complete proteinase inhibitor cocktail (Roche)) was added to final volume of $800 \mu$ l. The sample was rotated for $1-2 \mathrm{~h}$ at $4^{\circ} \mathrm{C}$ before $10 \mu \mathrm{l}$ of Protein A Dynabeads ${ }^{\circledR}$ (Life Technologies) were added and rotation continued overnight at $4^{\circ} \mathrm{C}$. After four washes with $500 \mu \mathrm{IP}$ buffer, precipitates were eluted in $40 \mu \mathrm{l}$ Lämmli sample buffer, separated by SDS-PAGE and analyzed by Western blot as indicated. Lysate equivalent to $20 \%$ of input was loaded as reference. Experiments were repeated 3 times.

For the immunoprecipitation from native cells, lysates from two confluent $15-\mathrm{cm}$ plates per cell-line (wild-type and $L R R C 8 A^{-/}$) were prepared as described above. $1.9 \mathrm{ml}$ lysate were mixed with equal volumes of IP buffer and $30 \mu$ of Protein A Dynabeads ${ }^{\circledR}$ (Life Technologies) previously coupled to $15 \mu \mathrm{g}$ of the LRRC8A antibody using dimethyl pimelimidate. After incubation and washing as described above, precipitates were eluted from the beads in $50 \mu \mathrm{l}$ of $0.2 \mathrm{M}$ glycine ( $\mathrm{pH} 2.5$ ), mixed with Lämmli sample buffer, separated by SDS-PAGE and analyzed by Western blot as indicated. 
To assess protein expression, cells were lysed as described above. Protein concentrations were determined by BCA and equal amounts were separated by SDS-PAGE and analyzed by Western blot as indicated.

\section{Taurine Efflux Experiments}

HEK or HCT116 cells were grown to $~ 80 \%$ confluency (48-72 h after plating) in $35-\mathrm{mm}$ diameter plates coated with poly-L-lysine. For rescue experiments, cells were transfected one day before flux measurements with LRRC8A and LRRC8C-GFP expression plasmids using Fugene HD. For these experiments, WT cells were mock transfected with a GFP expression vector. Cells were loaded with ${ }^{3}[\mathrm{H}]$-taurine $(2 \mu \mathrm{Ci} / \mathrm{ml}$; Perkin-Elmer) for 2 to $2.5 \mathrm{~h}$ in culture medium (without $\mathrm{FCS}$ ) at $37^{\circ} \mathrm{C}$. They were then washed 7 times at room temperature with isotonic solution (in $\mathrm{mM}$ : $150 \mathrm{NaCl}, 6 \mathrm{KCl}, 1 \mathrm{MgCl}_{2}, 1.5 \mathrm{CaCl}_{2}, 10$ glucose, 10 HEPES pH 7.4, 320 mOsm). After washing, external media were removed in 5-min intervals and replaced with fresh isotonic or hypotonic solution (in $\mathrm{mM}: 105 \mathrm{NaCl}, 6 \mathrm{KCl}, 1$ $\mathrm{MgCl}_{2}, 1.5 \mathrm{CaCl}_{2}, 10$ glucose, 10 HEPES pH 7.4, $240 \mathrm{mOsm}$ ) and saved for counting. At the end of the experiment, cells were lysed with $0.75 \mathrm{ml}$ of $0.1 \mathrm{M} \mathrm{NaOH}$. The radioactivity of cell supernatants and of the final cell lysate was determined in a liquid scintillation counter. Values presented were normalized to the total cellular radioactivity at that time point which was determined by adding the counts from the cell lysate and those of the supernatants collected at the corresponding and following time points. In each flux experiment, each data point represents the mean of 6 wells.

\section{RVD Measurements}

Cell volume was measured semiquantitatively using the calcein fluorescence method (38). HEK cells were plated 2 days before measurements at a density of 6,000 cells per well in a 384-well plate. For the RVD assay, $10 \mu \mathrm{M}$ calcein-AM (Affymetrix eBioscience) in DMEM were loaded for $1 \mathrm{~h}$ at $37^{\circ} \mathrm{C}$ and then washed 3 times with $80 \mu$ isotonic solution (in $\mathrm{mM}: 145$ $\mathrm{NaCl}, 5 \mathrm{KCl}, 1 \mathrm{MgCl}_{2}, 2 \mathrm{CaCl}_{2}, 10$ glucose, 10 HEPES pH 7.4, $329 \mathrm{mOsm}$ ) using a Tecan Freedom EVO 200 workstation. Finally $10 \mu \mathrm{l}$ of the isotonic solution were added to each well. After a 5-min incubation period the plate was transferred into the FLIPR ${ }^{\text {TM }}$ (Molecular Devices) and fluorescence measurements at $\lambda=515-575 \mathrm{~nm}$ were initiated using the FLIPR Fluo4 LED/filter set. After baseline recording for $25 \mathrm{~s}, 25 \mu \mathrm{l}$ aqua dest. were added to the wells resulting in a final osmolarity of 94 mOsm. Calcein fluorescence was monitored for $\sim 65$ min. Wells containing cells of the respective cell-line not loaded with calcein-AM (but otherwise treated equally) were used for background subtraction, and fluorescence values were normalized to $\mathrm{t}=30 \mathrm{~s}$ (after the pipetting procedure). Less pronounced swelling and RVD of WT HEK cells was observed under the conditions of our primary screen (exposure to $189 \mathrm{mOsm}$ ) and RVD was likewise abolished in $L R R C 8 A^{-/-}$cells (not shown). 


\section{Author contributions:}

F.K.V. and T.S. established and conducted the siRNA screen with K.L. and J.P.K., generated cell lines and antibodies, and designed, performed and analyzed molecular biological, biochemical and cell biological experiments. F.U. and J.M. designed, performed and analyzed patch-clamp experiments. D.L. performed taurine flux measurements. N.M. and M.A.A.-N. provided bioinformatics analysis. T.J.J. designed and analyzed experiments and wrote the paper with critical input of all authors.

\section{Supplementary Figures}

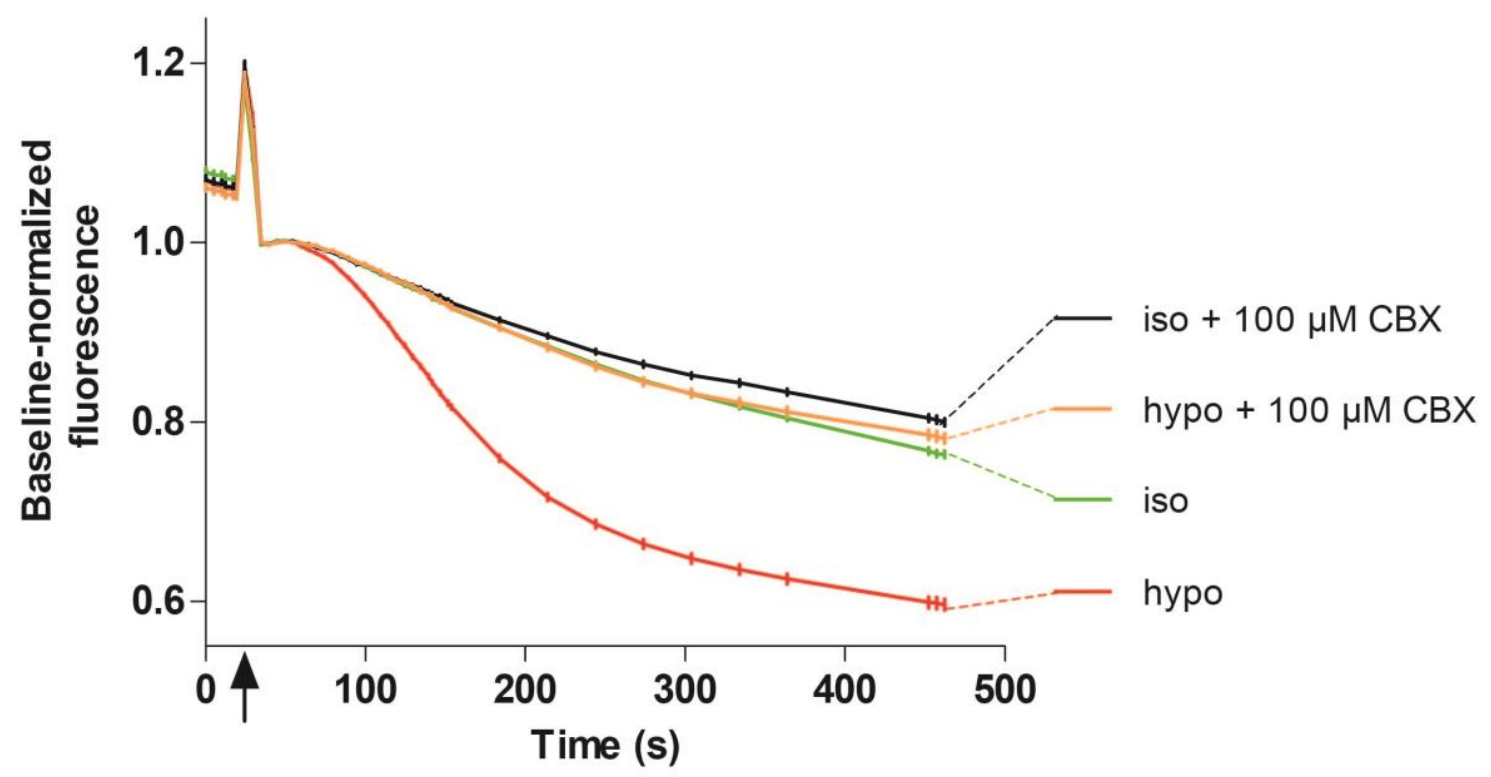

Fig. S1. Effect of carbenoxolone on hypotonicity-induced YFP quenching by iodide. Fluorescence trace from a FLIPR ${ }^{\mathrm{TM}}$ experiment similar to those in Fig. $1 \mathrm{C}$ in which the effect of carbenoxolone (CBX), an inhibitor of VRAC and gap junctions (18), was investigated. Carbenoxolone was included in the $\mathrm{I}^{-}$-containing solution and added at the time point indicated by arrow. 

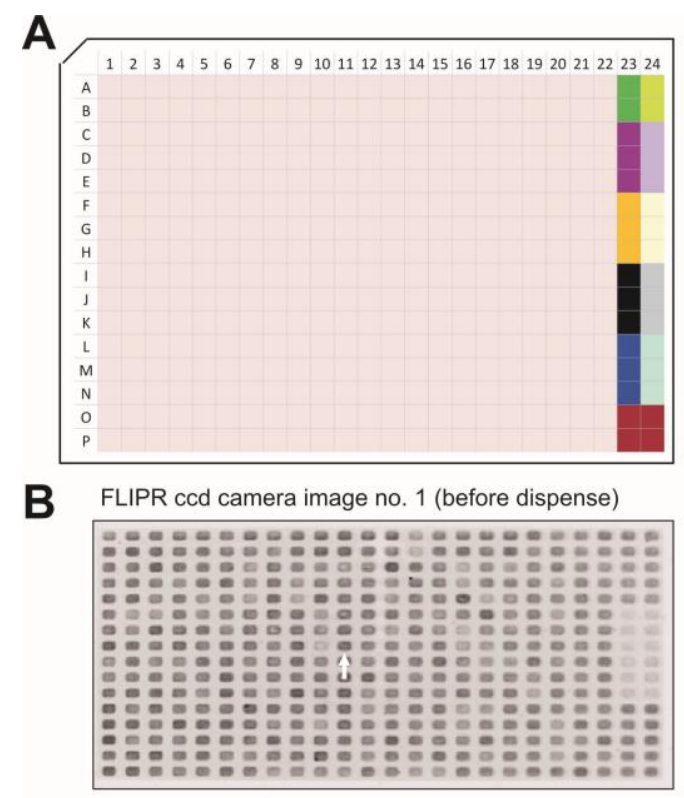

FLIPR ccd camera image no. 9 (end of measurement)

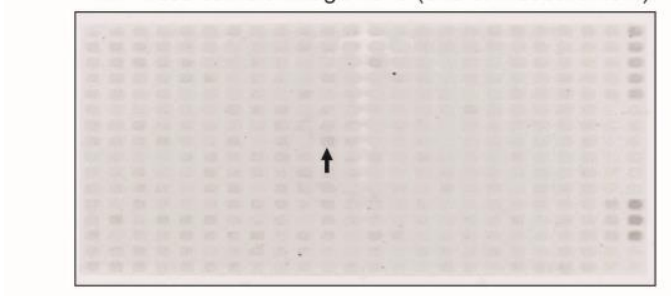

C

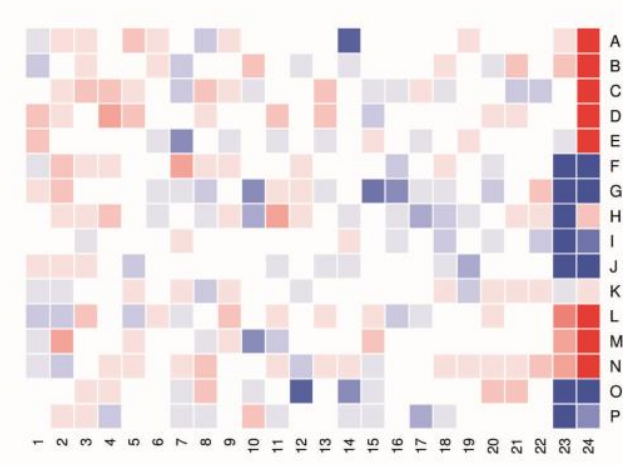

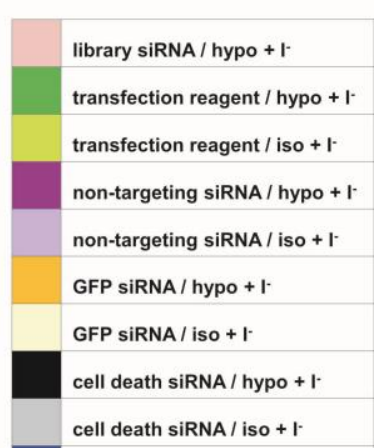

cell death SiRNA $/$ iso +

SLC4A2 SIRNA / hypo + I-

SLC4A2 SIRNA / iso + 1.

TritonX in hypo $+\mathbf{i}$

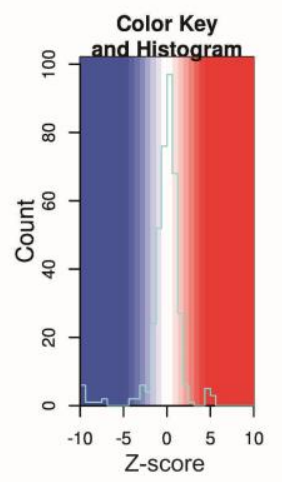

Fig. S2. Genome-wide RNA interference screen for VRAC. (A) Plate lay-out. Cells in wells of rows 1-22 were transfected with individual siRNAs of the Ambion Silencer ${ }^{\circledR}$ Human Genome siRNA Library V3 and tested for hypotonicity-induced YFP-quenching (experimental wells). Rows 23 and 24 contained control wells that were treated as indicated. (B) Photograph (inverted) of YFP fluorescence of an entire plate before the pipetting step (top) and at the end of the experiment (below). Note that fluorescence of cells treated with siRNA against YFP and cell-death inducing siRNA is strongly reduced at the beginning of the experiment (top) (transfection control). At the end of the experiment (bottom), fluorescence has remained strong in wells remaining in isotonic solution throughout. Arrows indicate well $\mathrm{H} 11$ containing cells transfected with the most efficient siRNA against $L R R C 8 A$. (C) Heat map of the same plate. Z-scores for $S_{\max }$ (maximal slope of quenching) are displayed using the color scale shown at right. 

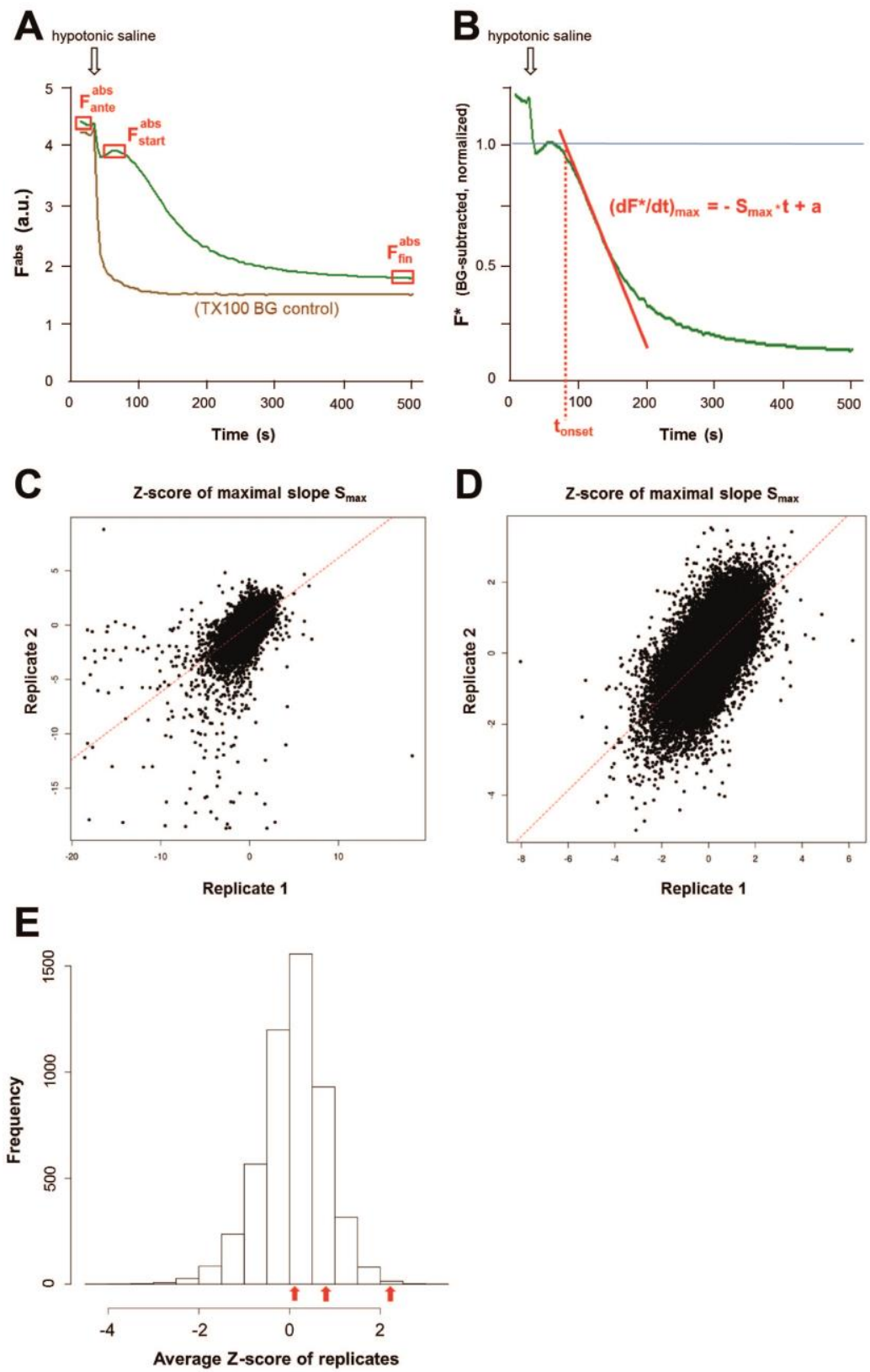

Fig. S3. Analysis of the primary, genome-wide siRNA screen for VRAC. (A and B) Parameters derived from the primary siRNA screen for VRAC. (A) Example of original data obtained from the FLIPR ${ }^{\mathrm{TM}}$ primary genome-wide screen, showing the absolute, noncorrected values of fluorescence $\left(F^{\text {abs }}\right)$ measured at $\lambda=526-585 \mathrm{~nm}$ as a function of time. The green curve shows a representative trace from an experimental well with YFPexpressing HEK cells that have been treated with siRNA and were exposed to hypotonic, iodide-containing solution at the time indicated by the arrow. The brown curve shows a control well from the same plate to which hypotonic, iodide-containing solution containing $1 \%$ Triton X100. (B) Background-subtracted and normalized fluorescence $F^{\star}$. After subtracting the background determined in control wells treated with Triton X100, the fluorescence of 
every experimental well was normalized to its individual $\mathrm{F}_{\text {start }}^{\mathrm{abs}}$ value. The maximal slope of fluorescence decrease $S_{\max }$ was determined by linear regression to the curve between 35 and 300 seconds and was used as main parameter to identify hits. $t_{\text {onset }}$ was defined as indicated and can be used as measure of the speed of signal transduction between volume increase and VRAC opening. (C and D) Fidelity of replicate screens. Correlation of Z-scores of maximal slope $S_{\max }$ between the original and the replicate screen observed with all 65,061 siRNAs $(C)$ and after filtering out those measurements that were flagged for low cell number or did not reach near-steady-state fluorescence by the end of the measurement (D). Z-scores from screen 1 and screen 2 are plotted on the $x$ - and $y$-axis, respectively. The Pearson correlation coefficient ( $r=0.62$ and $r=0.65$, respectively) indicates positive correlation between replicate screens. The regression line from simple linear regression is shown as a dashed red line. The elimination of outliers demonstrated the usefulness of these warning flags. (E) Histogram of Z-scores for maximal slope $\left(S_{\max }\right)$ from the genome-wide siRNA screen. Measurements which were flagged for low cell number or did not reach steady state fluorescence by the end of measurement were filtered out, resulting in values for 50,258 siRNAs. The averaged Z-scores from screen 1 and screen 2 are plotted. Arrows indicate the Z-scores of three individual siRNAs against $L R R C 8 A(0.125,0.809$ and 2.217$)$. 


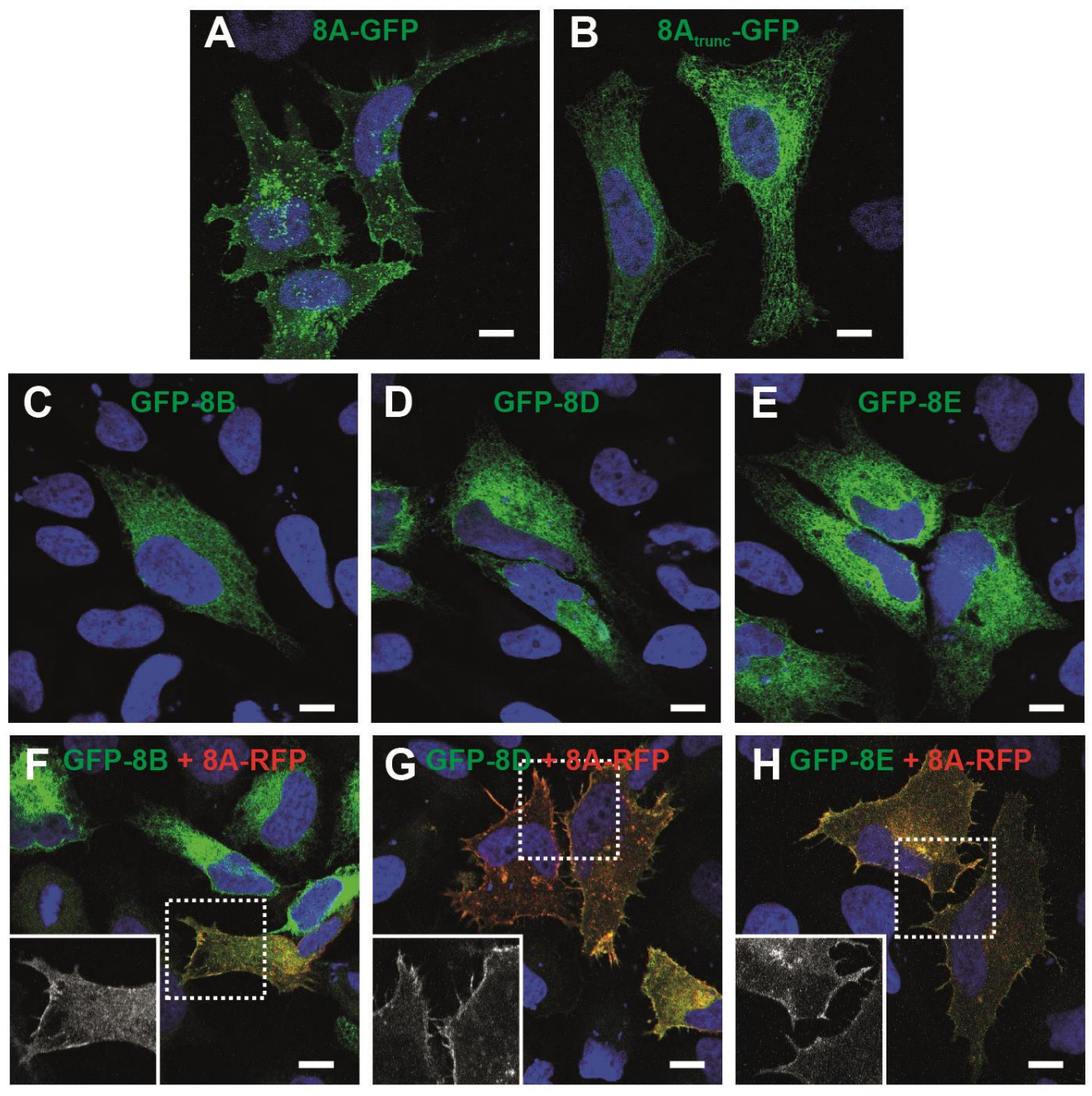

Fig. S4. Subcellular localization of LRRC8 proteins. (A) Plasma membrane localization of LRRC8A-GFP transfected into HeLa cells detected by GFP labeling. (B) Truncated LRRC8A fused at R719 to GFP failed to reach the plasma membrane. This truncation mimics the effect of a chromosomal translocation at the $L R R C 8 A$ that was found in a patient with agammaglobulinemia (21). (C-E) Intracellular localization of LRRC8B, D and E when transfected alone (for LRRC8C, see Fig 1I). (F-H) LRRC8B, D and E reach the plasma membrane when co-transfected with LRRC8A (for LRRC8C, see Fig 1J). Insets, magnification of boxed areas showing exclusively GFP fluorescence. Scale bar, $10 \mu \mathrm{m}$ for all panels. 
A

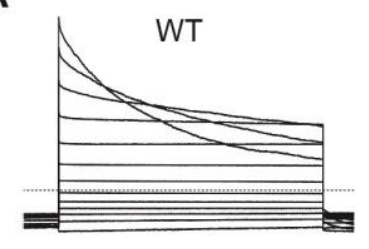

$\angle R R C 8 A^{-1-}$
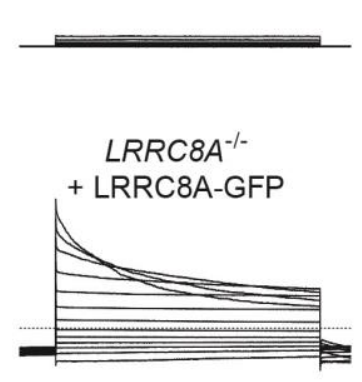

B

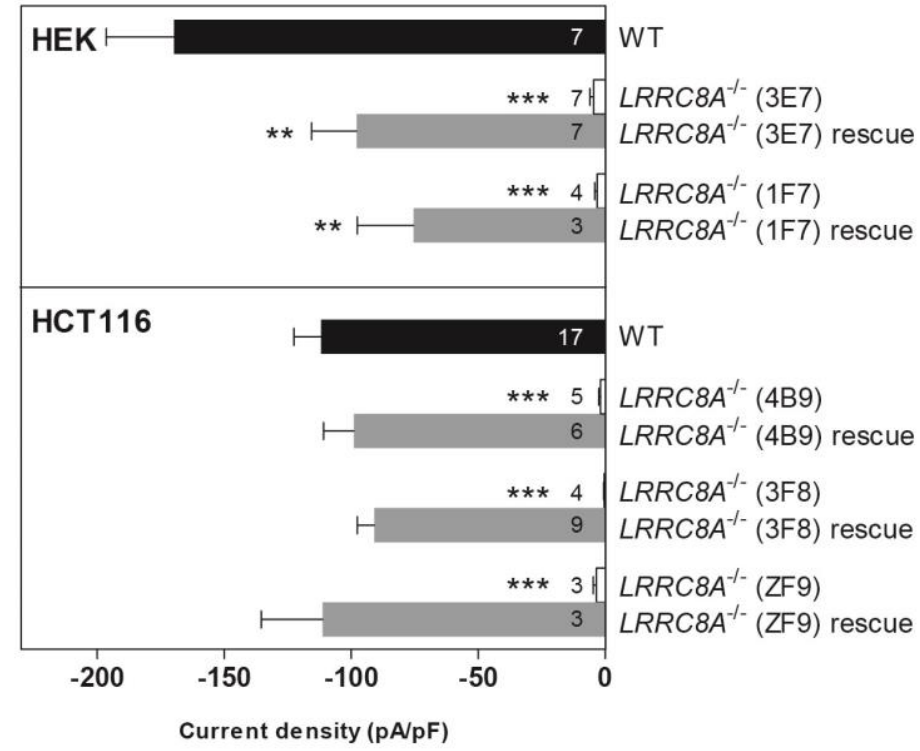

Fig. S5. Absence of $\mathrm{I}_{\mathrm{Cl}(\text { swell) }}$ in independent $L R \boldsymbol{R} C \boldsymbol{A}^{-/-}$cell lines. (A) Example $\mathrm{I}_{\mathrm{Cl}(\text { swell) }}$ traces (as in Fig. 1E, but 2-s pulses) of WT and mutant HEK cells (clone 3E7). When transfected into HEK $L R R C 8 A^{-/-}$cells, LRRC8A rescues $\mathrm{I}_{\mathrm{CI}(\text { swell). }}$ (B) Amplitudes of maximally activated $\mathrm{I}_{\mathrm{Cl}(\text { swell) }}\left(\right.$ at $-80 \mathrm{mV}$ ) of WT HEK, WT HCT116 and different $L R R C 8 A^{-/}$cell lines, rescued by transfection of LRRC8A-GFP cDNA. Note that the amplitude of $\mathrm{I}_{\mathrm{Cl}(\text { swell) }}$ current was not fully rescued in HEK cells by LRRC8-GFP transfection, an observation that fits to the suppression of $\mathrm{I}_{\mathrm{Cl}(\text { swell) }}$ from native HEK cells by LRRC8A transfection (Fig. 1F). Mean currents $\pm \mathrm{SEM}$, number of measurements is indicated. ${ }^{* *}, p<0.01$ and ${ }^{* * *}, p<0.001$ compared to WT HEK or WT HCT116, respectively. For description of different cell lines see table S4. 
A

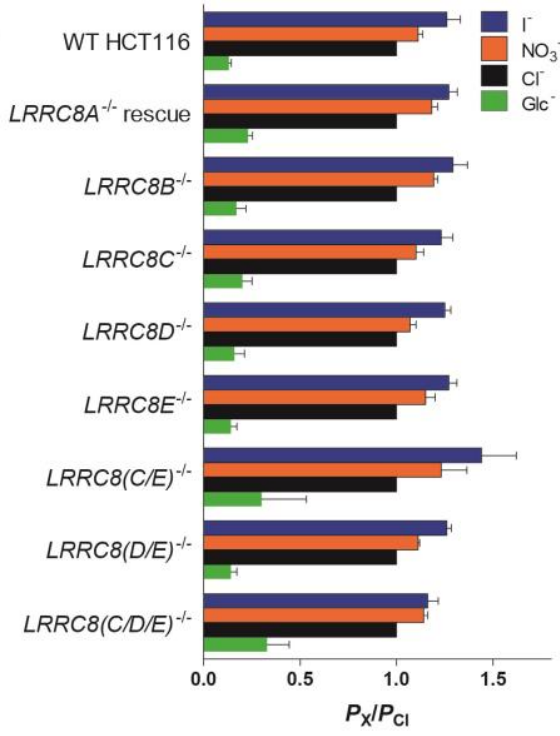

B

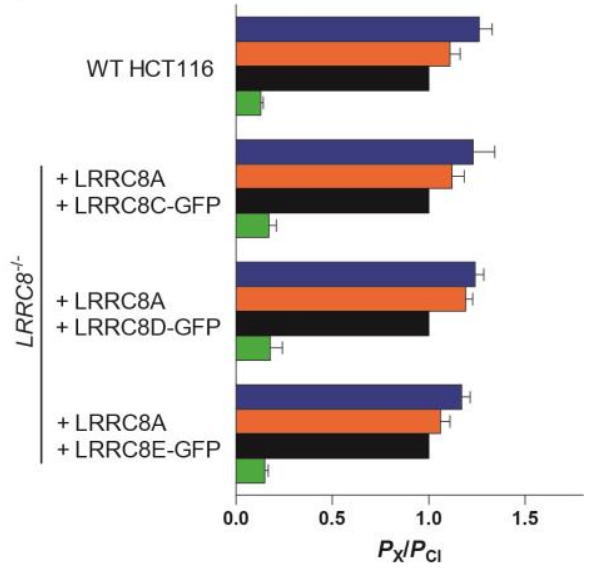

C

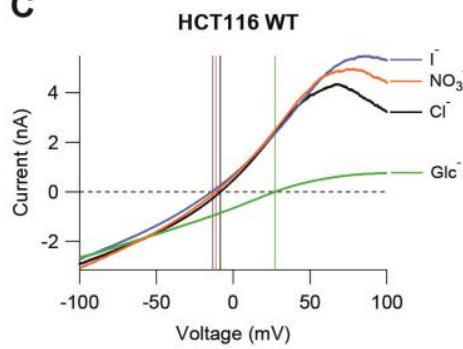
LRRC8
+ LRRC8A + LRRC8D
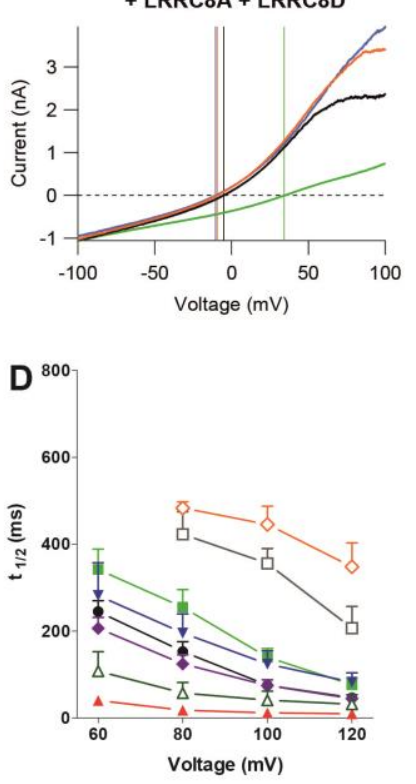

- WTHCT116 (9) $\mathbf{\text { VRRC8E }}{ }^{-1}(7)$

= $L R R C 8 B^{-/ 2}(5) \quad \triangle L R R C 8(C / E)^{-/ 2}(5)$

4 $L R R C 8 C^{-1-}(5) \diamond \operatorname{LRRC8}(D / E)^{-/-}{ }_{(4)}$

- $\operatorname{LRRC8D}^{-1-}{ }_{(6)} \quad \square$ WTHEK $(6)$

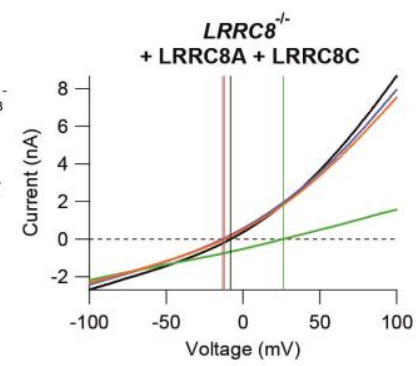

LRRC8 ${ }^{-1-}$ + LRRC8A + LRRC8E
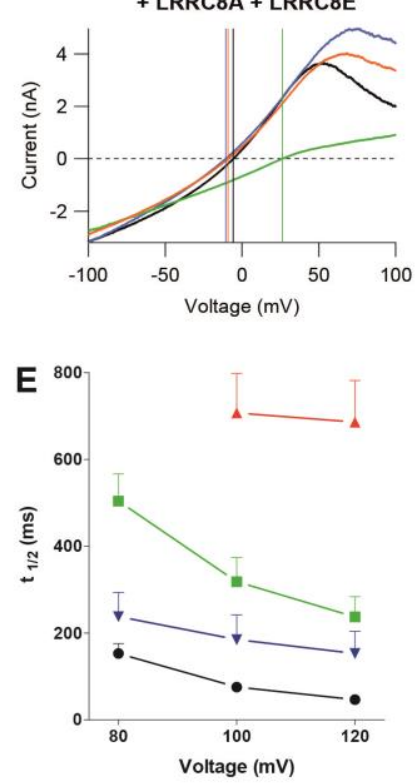

- WT HCT116 (9)

A LRRC8A + LRRC8C-GFP (7)

= LRRC8A + LRRC8D-GFP (5)

v LRRC8A + LRRC8E-GFP (8)

Fig. S6. Characterization of $\mathrm{I}_{\mathrm{Cl}(\text { swell) }}$ in HCT116 cells. (A) Relative anion permeabilities $\left(P_{\mathrm{X}} / P_{\mathrm{Cl}}\right)$ as determined from shifts in reversal potential of $\mathrm{I}_{\mathrm{Cl}(\text { swell) }}$ upon anion substitution in WT, LRRC8 knock-out HCT116 cell lines, and (B) $L R R C 8^{-/}$cells transfected with the combinations indicated. Mean \pm SEM, number of cells $\geq 4$. (C) Example current-voltage relationships obtained at the time of maximal current activation of endogenous and reconstituted $\mathrm{I}_{\mathrm{Cl}(\text { swell) }}$ with normal and anion substituted hypotonic extracellular solutions. The reversal potential is shifted to slightly more negative voltages when extracellular $\mathrm{Cl}^{-}$is replaced by $\mathrm{I}^{-}$and $\mathrm{NO}_{3}{ }^{-}$and to drastically more positive voltages upon replacement by $\mathrm{D}-$ gluconate. (D-E) Voltage-dependent $\mathrm{I}_{\mathrm{Cl}(\text { swell) }}$ inactivation assessed by time needed to inactivate to $50 \%$ of the difference between currents at end / beginning of pulse $\left(I_{2 \sec } / I_{\max }\right)$. In panel $\mathrm{E}$, constructs were transfected into the quintuple KO HCT116 cell line $\left(L R R C 8^{-/}\right)$. Numbers in brackets indicate the number of cells measured. 


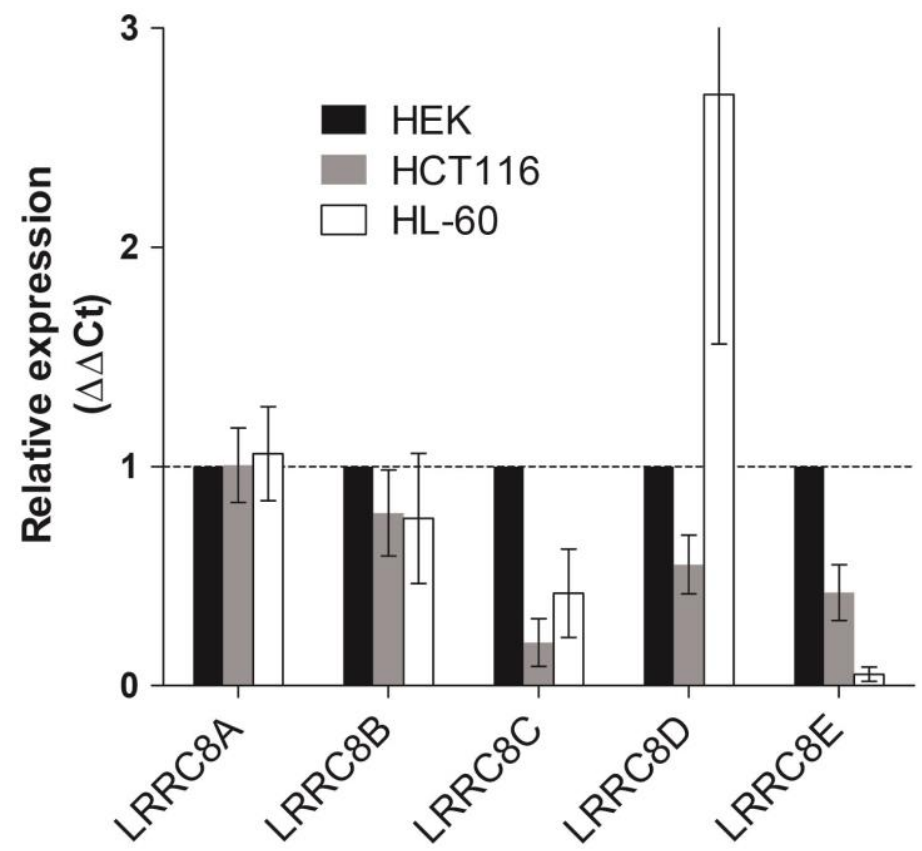

Fig S7. Relative LRRC8 mRNA expression. LRRC8A - E mRNA expression in HEK, HCT116, and HL-60 cells determined by quantitative RT-PCR. Values were normalized to the respective value of HEK cells. Values represent the means from 4 experiments. Error bars indicate SEM.

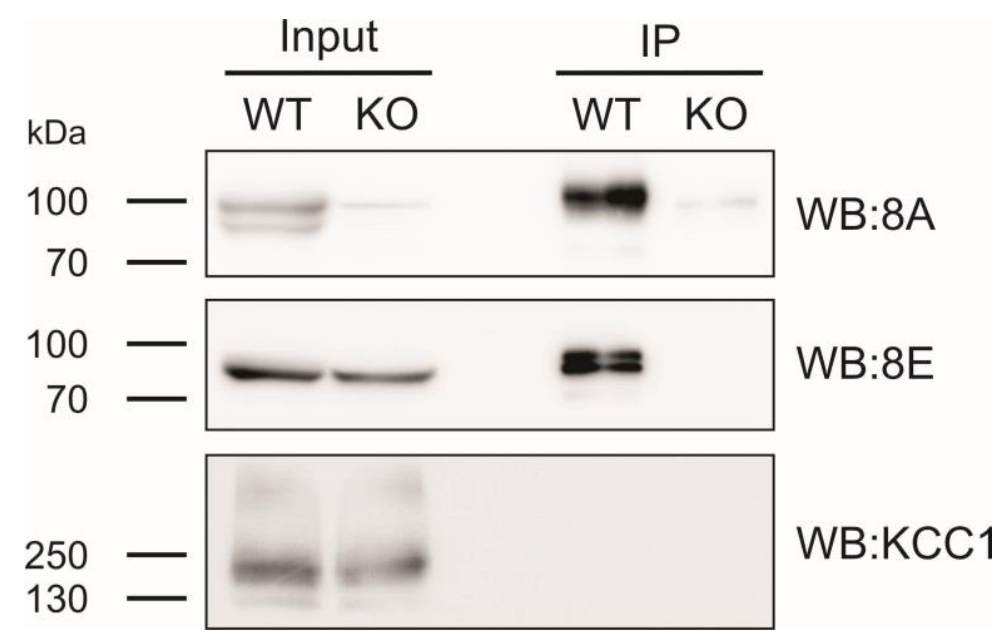

Fig. S8. Heteromerization of endogenous LRRC8 proteins. LRRC8A co-precipitated LRRC8E (for which a suitable antibody was available) in immunoprecipitation with an LRRC8A antibody from wild-type (WT) HEK cell lysate, but not from the $L R R C 8 A^{-1}$ knockout (KO, clone 3E7). The plasma membrane ion transporter KCC1 (negative control) did not coprecipitate with LRRC8A. Lysate equivalent to $25 \%$ of input was loaded as reference (input). 



Fig. S9. LRRC8A is crucial for swelling-induced ${ }^{3}[\mathrm{H}]$-taurine efflux in HEK cells. (A) One set of wild-type (WT) HEK cells were in isotonic solution throughout, whereas another set of WT or $L R R C 8 A^{-/-} \mathrm{HEK}$ cells were exposed to hypotonic solution starting at $\mathrm{t}=0$ (arrow). Bars represent means of 6 measurements of taurine efflux between the indicated time points. Error bars indicate SEM. (B) Taurine efflux measurement as in (A), but the $L R R C 8 A^{-1-}$ HEK cells had been co-transfected with LRRC8A and LRRC8C-GFP. This cotransfection partially restores the taurine flux capability of $L R R C 8 A^{-/}$HEK cells. Cotransfection was necessary as overexpression of LRRC8A alone leads to a suppression of

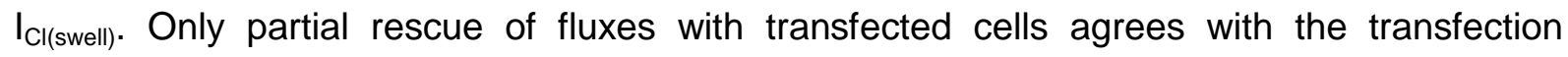
efficiency of roughly $50 \%$. 
A

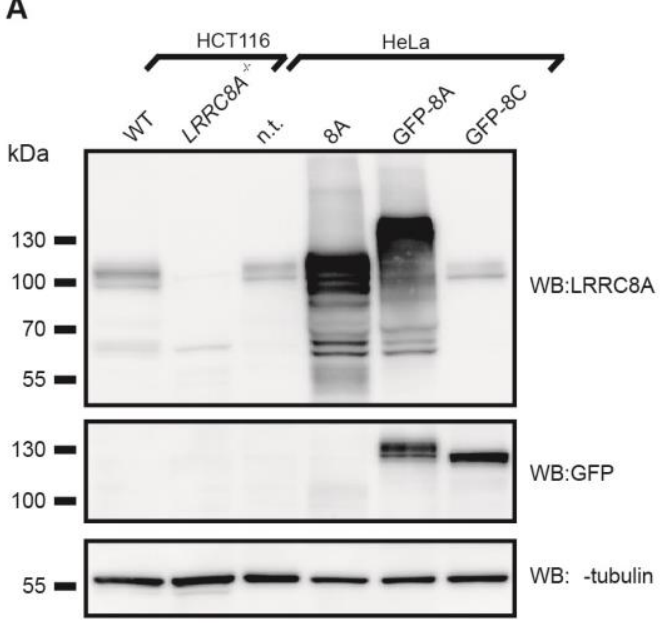

C
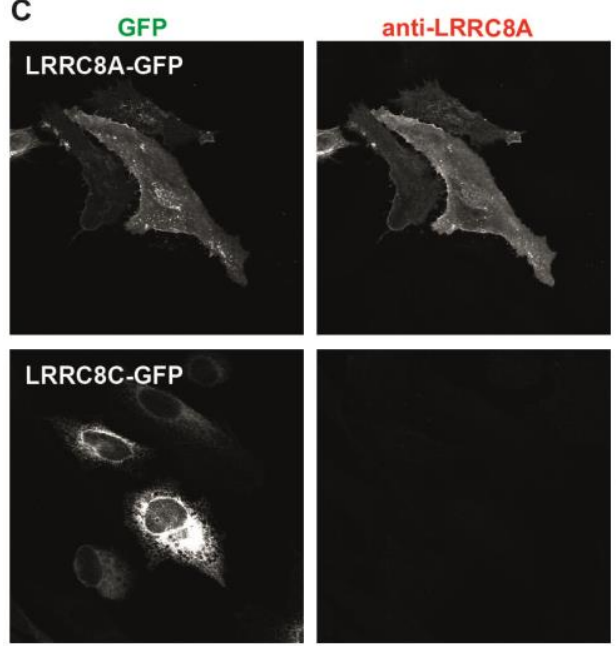
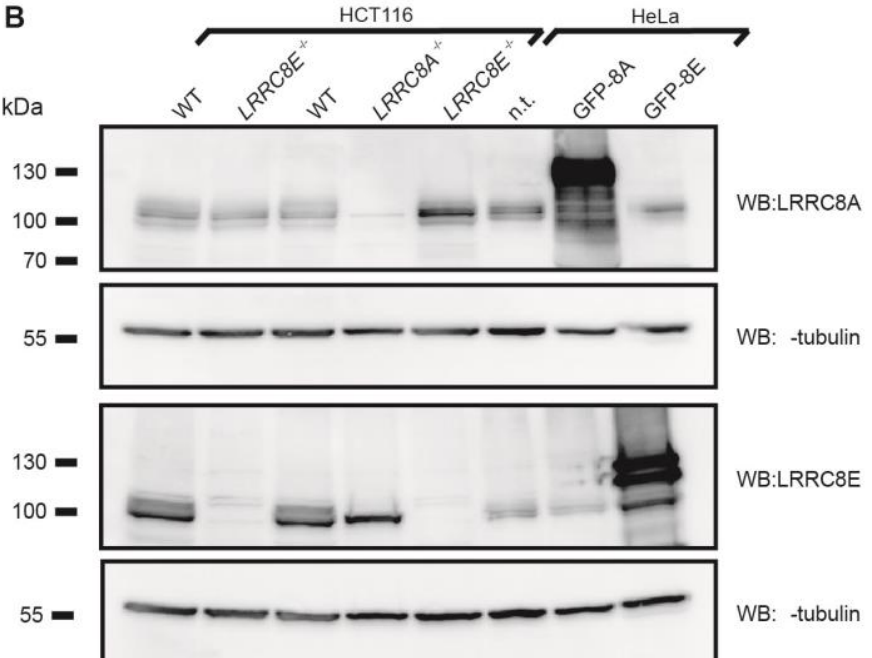

overlay

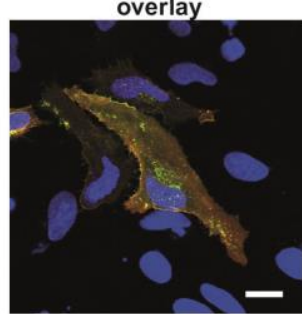

D

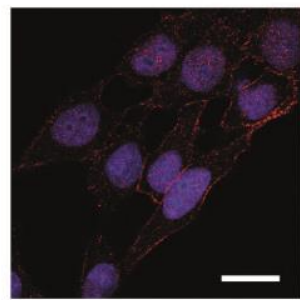



Fig. S10. Characterization of LRRC8A and LRRC8E antibodies. (A) Western blots of lysates from wild-type (WT) and LRRC8A $A^{-/}$(clone 3F8) HCT116 cells, and from HeLa cells that were not transfected (n.t.), or transfected with LRRC8A or with LRRC8A and LRRC8C GFP fusion proteins were probed with the LRRC8A antibody, or antibodies against GFP and a-tubulin (loading control) as indicated. The LRRC8A antibody recognizes native and overexpressed LRRC8A specifically. (B) Western blots of lysates from WT, $L R R C 8 A^{-/ 2}$ (clone 4B9) and LRRC8E ${ }^{/-}$(clones BCDE(WT)-F5 and CE(WT)-B6) HCT116 cells, and from HeLa cells that were not transfected (n.t.) or transfected with LRRC8A or LRRC8E GFP fusion proteins were probed with antibodies against LRRC8A, LRRC8E and $\alpha$-tubulin. The LRRC8E antibody recognizes specifically native and overexpressed LRRC8E, whereas LRRC8E is not recognized by the LRRC8A antibody. (C) HeLa cells methanol-fixed and immunostained with the LRRC8A antibody (red in overlay) $24 \mathrm{~h}$ after transfection with LRRC8A (upper panel) and LRRC8C (bottom panel) GFP fusion proteins (GFP signal, green in overlay), nuclei in blue. The LRRC8A antibody recognizes specifically overexpressed LRRC8A. Scale bars, $20 \mu \mathrm{m}$. (D) Higher exposure of non-transfected HeLa cells reveals plasma membrane staining with the LRRC8A antibody (red; nuclei in blue). Scale bar, $20 \mu \mathrm{m}$. 


\section{Supplementary Tables}

Table S1. List of anion transporters tested by siRNA interference in HEK cells in a FLIPR $^{\mathrm{TM}}$ prescreen.

\begin{tabular}{|c|c|c|}
\hline Gene name & Alternative name(s) & Proposed function \\
\hline ANO1 & Anoctamin1, TMEM16A & $\mathrm{Ca}^{2+}$-activated $\mathrm{Cl}^{-}$channel \\
\hline ANO3 & Anoctamin3, TMEM16C & $\mathrm{Ca}^{2+}$-activated $\mathrm{Cl}^{-}$channel (?) \\
\hline ANO4 & Anoctamin4, TMEM16D & $\mathrm{Ca}^{2+}$-activated $\mathrm{Cl}^{-}$channel (?) \\
\hline ANO5 & Anoctamin5, TMEM16E & $\mathrm{Ca}^{2+}$-activated $\mathrm{Cl}^{-}$channel (?) \\
\hline ANO6 & Anoctamin6, TMEM16F & $\mathrm{Ca}^{2+}$-activated $\mathrm{Cl}^{-}$or cation channel, scramblase \\
\hline ANO7 & Anoctamin7, TMEM16G & $\mathrm{Ca}^{2+}$-activated $\mathrm{Cl}^{-}$channel (?) \\
\hline ANO8 & Anoctamin8, TMEM16H & $\mathrm{Ca}^{2+}$-activated $\mathrm{Cl}^{-}$channel (?) \\
\hline ANO9 & Anoctamin9, TMEM16J & $\mathrm{Ca}^{2+}$-activated $\mathrm{Cl}^{-}$channel (?) \\
\hline ANO10 & Anoctamin10, TMEM16K & $\mathrm{Ca}^{2+}$-activated $\mathrm{Cl}^{-}$channel (?) \\
\hline CLCN3 & $\mathrm{ClC}-3$ & $\mathrm{Cl}^{-} / \mathrm{H}^{+}$-exchanger, wrongly claimed to be VRAC \\
\hline BEST1 & Bestrophin 1 & $\mathrm{Ca}^{2+}$-activated $\mathrm{Cl}^{-}$channel \\
\hline BEST2 & Bestrophin 2 & $\mathrm{Ca}^{2+}$-activated $\mathrm{Cl}^{-}$channel \\
\hline$S L C 4 A 2$ & AE2, anion exchanger 2 & $\mathrm{Cl}^{-} / \mathrm{HCO}_{3}^{-}$exchanger \\
\hline$S L C 4 A 3$ & AE3, anion exchanger 3 & $\mathrm{Cl}^{-} / \mathrm{HCO}_{3}{ }^{-}$exchanger \\
\hline SLC12A2 & NKCC1 & $\mathrm{NaK} 2 \mathrm{Cl}$ cotransporter \\
\hline SLC12A4 & KCC1 & $\mathrm{KCl}$ cotransporter \\
\hline SLC12A6 & KCC3 & $\mathrm{KCl}$ cotransporter \\
\hline SLC12A7 & KCC4 & $\mathrm{KCl}$ cotransporter \\
\hline SLC26A1 & SAT1 & anion exchanger, sulfate transporter \\
\hline SLC26A9 & & anion transporter \\
\hline SLC26A11 & KBAT & $\mathrm{Na}^{+}$-dependent sulfate transporter, $\mathrm{Cl}^{-}$channel (?) \\
\hline
\end{tabular}


Table S2. List of candidate genes from genome-wide siRNA screen that were taken into a secondary FLIPR $^{\mathrm{TM}}$ RNA interference screen using SMARTpools of independent siRNAs.

\begin{tabular}{|c|c|c|c|c|c|c|c|c|c|}
\hline & Gene ID & Gene symbol & TMDs* & Z-score ${ }^{\dagger}$ & & Gene ID & Gene symbol & TMDs* & Z-score ${ }^{\dagger}$ \\
\hline 1 & 3371 & $T N C$ & 1 & 2.6931 & 45 & 51338 & $M S 4 A 4 A$ & 4 & 1.3255 \\
\hline 2 & 79652 & TMEM204 & 4 & 2.3119 & 46 & 92255 & $D K F Z p 434 H 2226$ & 9 & 1.3153 \\
\hline 3 & 253558 & ALCAT1 & 3 & 2.1069 & 47 & 79762 & FLJ14146 & 1 & 1.3139 \\
\hline 4 & 54879 & $S T 7 L$ & 2 & 1.9163 & 48 & 159371 & TMEM20 & 10 & 1.3091 \\
\hline 5 & 5793 & PTPRG & 1 & 1.8685 & 49 & 79683 & ZDHHC14 & 4 & 1.3016 \\
\hline 6 & 28959 & LR8 / TMEM176B & 4 & 1.8351 & 50 & 65062 & ALS2CR4 & 4 & 1.2954 \\
\hline 7 & 51234 & EMC4 & 2 & 1.7410 & 51 & 79844 & ZDHHC11 & 5 & 1.2780 \\
\hline 8 & 10098 & TM4SF9/TSPAN5 & 4 & 1.7358 & 52 & 10100 & TSPAN-2 & 4 & 1.2743 \\
\hline 9 & 125111 & GJC1/GJD3 & 4 & 1.7326 & 53 & 123606 & NIPA1 & 8 & 1.2581 \\
\hline 10 & 29940 & SART2 & 3 & 1.6643 & 54 & 55362 & TMEM63B & 11 & 1.2448 \\
\hline 11 & 284723 & SLC25A34 & 2 & 1.6399 & 55 & 124491 & TMEM170A & 3 & 1.2369 \\
\hline 12 & 130814 & PQLC3 & 4 & 1.6306 & 56 & 56674 & TMEM9B & 2 & 1.2335 \\
\hline 13 & 23505 & RW1/TMEM131 & 2 & 1.6096 & 57 & 94015 & TTYH2 & 6 & 1.2300 \\
\hline 14 & 199953 & TMEM201 & 6 & 1.5948 & 58 & 203562 & TMEM31 & 2 & 1.2116 \\
\hline 15 & 80759 & $K H D C 1$ & 2 & 1.5846 & 59 & 27069 & GHITM & 6 & 1.2099 \\
\hline 16 & 9415 & FADS2 & 4 & 1.5817 & 60 & 26526 & $T M 4-B$ & 3 & 1.1928 \\
\hline 17 & 57484 & $R N F 150$ & 2 & 1.5569 & 61 & 81671 & VMP1 & 6 & 1.1703 \\
\hline 18 & 54741 & OBRGRP & 4 & 1.5488 & 62 & 374882 & TMEM205 & 4 & 1.1329 \\
\hline 19 & 5348 & FXYD1 & 1 & 1.5477 & 63 & 10712 & Fam189B & 4 & 1.1222 \\
\hline 20 & 56172 & $A N K H$ & 8 & 1.5316 & 64 & 85414 & Prostein/SLC45A3 & 11 & 1.1208 \\
\hline 21 & 4034 & $\mathrm{LRCH} 4$ & 1 & 1.5303 & 65 & 91147 & TMEM67 & 4 & 1.1122 \\
\hline 22 & 57198 & ATP8B2 & 9 & 1.5268 & 66 & 57348 & TTYH1 & 5 & 1.0725 \\
\hline 23 & 53346 & TM6SF1 & 9 & 1.5216 & 67 & 128506 & OCSTAMP & 6 & 1.0707 \\
\hline 24 & 120224 & TMEM45B & 5 & 1.5205 & 68 & 55852 & TEX2 & 2 & 1.0702 \\
\hline 25 & 56262 & LRRC8A & 4 & 1.5129 & 69 & 93109 & TMEM44 & 4 & 1.0630 \\
\hline 26 & 10959 & $R N P 24$ & 2 & 1.4911 & 70 & 11161 & C14orf1 & 4 & 1.0598 \\
\hline 27 & 79022 & TMEM106C & 2 & 1.4885 & 71 & 64137 & $A B C G 4$ & 7 & 1.0392 \\
\hline 28 & 349149 & GJE1/GJC3 & 3 & 1.4769 & 72 & 29097 & HSPC163 & 3 & 1.0315 \\
\hline 29 & 746 & TMEM258 & 2 & 1.4751 & 73 & 55625 & ZDHHC7 & 4 & 1.0268 \\
\hline 30 & 53827 & FXYD5 & 1 & 1.4684 & 74 & 64429 & ZDHHC6 & 4 & 1.0165 \\
\hline 31 & 55009 & C19orf24 & 2 & 1.4654 & 75 & 54860 & MS4A12 & 4 & 1.0130 \\
\hline 32 & 29058 & C20orf30 & 2 & 1.4566 & 76 & 162427 & FAM134C & 3 & 1.0120 \\
\hline 33 & 10099 & TM4SF8/ TSPAN3 & 4 & 1.4361 & 77 & 23460 & $A B C A 6$ & 13 & 1.0099 \\
\hline 34 & 54929 & TMEM161A & 8 & 1.4268 & 78 & 9906 & SLC35E2 & 3 & 0.9891 \\
\hline 35 & 84561 & SLC12A8 & 10 & 1.4140 & 79 & 64645 & HIAT1 & 12 & 0.9848 \\
\hline 36 & 113829 & $S L C 35 A 4$ & 9 & 1.4016 & 80 & 345274 & SOAT/SLC10A6 & 8 & 0.9758 \\
\hline 37 & 29956 & LASS2 & 5 & 1.3728 & 81 & 347735 & TDE2L/SERINC2 & 11 & 0.9695 \\
\hline 38 & 145407 & C14orf37 & 2 & 1.3710 & 82 & 55002 & ТМСО3 & 10 & 0.9674 \\
\hline 39 & 51522 & TMEM14C & 4 & 1.3670 & 83 & 202915 & TMEM184A & 7 & 0.9488 \\
\hline 40 & 55739 & FLJ10769 & 1 & 1.3656 & 84 & 8082 & SSPN & 4 & 0.9236 \\
\hline 41 & 284099 & C17orf78 & 1 & 1.3551 & 85 & 84548 & FAM11A/TMEM185A & 8 & 0.9025 \\
\hline 42 & 81555 & $S M A P-5$ & 4 & 1.3487 & 86 & 135656 & DPCR1 & 2 & 0.8911 \\
\hline 43 & 57181 & SLC39A10 & 7 & 1.3480 & 87 & 85013 & TMEM128 & 4 & 0.7763 \\
\hline 44 & 7355 & $S L C 35 A 2$ & 8 & 1.3401 & & & & & \\
\hline
\end{tabular}

*predicted number of transmembrane domains

'mean Z-score for $\mathrm{S}_{\max }$ of the two 'best' siRNAs from 2 replicate primary screens 
Table S3. Clonal cell lines with disrupted $L R R C 8$ genes.

\begin{tabular}{|c|c|c|c|c|c|}
\hline Cell line & Clone name & Construct used $^{\star}$ & Genetic modification & Protein modification & Used for figure \\
\hline \multirow[t]{2}{*}{$\begin{array}{l}\angle R R C 8 A^{-/ 2} \\
\text { (HEK) }\end{array}$} & $3 \mathrm{E} 7$ & $3 A$ & $\begin{array}{l}\text { a1: } \Delta 21 \mathrm{nt}(\mathrm{t} 110-\mathrm{a} 130) \\
\text { a2: insertion of } 1 \mathrm{nt} \\
\text { (t after c123) }\end{array}$ & $\begin{array}{l}\text { A1: } \triangle M 37-G 43 \text { in TMD1 } \\
\text { (non- functional) } \\
\text { A2: G42W-fs in TMD1 }\end{array}$ & $\begin{array}{l}\text { Fig. } 1 \mathrm{H} \text {; Fig. } 2 \mathrm{~A} ; \\
\text { Fig. } 4 \mathrm{~B} ; \text {;ig. } 55 \\
\text { fig. S8; fig. S9 }\end{array}$ \\
\hline & $1 \mathrm{~F} 7$ & $1 \mathrm{~A}$ & $\begin{array}{l}\text { a1: } \Delta 9 \mathrm{nt}(\mathrm{a} 958-\mathrm{g} 966) \\
\text { a2: } \Delta 2 \mathrm{nt}(\mathrm{c} 965-\mathrm{g} 966) \\
\text { a3: } \Delta 23 \mathrm{nt}(\mathrm{a} 958-\mathrm{g} 980)\end{array}$ & $\begin{array}{l}\text { A1: } \Delta 1320-A 322 \text { at start of TMD4(non- } \\
\text { functional) } \\
\text { A2: A322V-fs at start of TMD4 } \\
\text { A3: I320P-fs at start of TMD4 }\end{array}$ & Fig. 2A; fig. S5B \\
\hline \multirow[t]{3}{*}{$\begin{array}{l}\mathrm{LRRC}^{-/} \\
\text {(HCT116) }\end{array}$} & $3 F 8$ & $3 A$ & $\Delta 2 \mathrm{~g}$ out of $6 \mathrm{~g}(\mathrm{~g} 124-\mathrm{g} 129)$ & G43D-fs in TMD1 & $\begin{array}{l}\text { Fig. 2A, 2B, 2C; } \\
\text { fig. S5B; fig. S6A; } \\
\text { fig. S10A }\end{array}$ \\
\hline & 4B9 & $4 \mathrm{~A}$ & $\begin{array}{l}\text { a1: } \Delta 32 \mathrm{nt}(\mathrm{c} 195-\mathrm{g} 226) \\
\text { a2: duplication of t206 }\end{array}$ & $\begin{array}{l}\text { A1: C65W-fs between TMD1 and TMD2 } \\
\text { A2: R70P-fs between TMD1 and TMD2 }\end{array}$ & $\begin{array}{l}\text { Fig. 2A; Fig. 4A; } \\
\text { fig. S5B; fig. S10B }\end{array}$ \\
\hline & ZF9 & ZFN & $\begin{array}{l}\text { a1: } \Delta 2 \text { nt (a508-c509) } \\
\text { a2: insertion of } 5 \text { nt (cacga after } \\
\text { a511) }\end{array}$ & $\begin{array}{l}\text { A1: T170E-fs between TMD2 and TMD3 } \\
\text { A2: R171T-fs between TMD2 and TMD3 }\end{array}$ & Fig. 2A; fig. S5B \\
\hline $\begin{array}{l}\angle R R C 8 B^{-/} \\
\text {(HCT116) }\end{array}$ & n2B-D3 & $2 \mathrm{~B}$ & duplication of t446 & E150R-fs after TMD2 & $\begin{array}{l}\text { Fig. 2B, 2C, 2D; } \\
\text { fig. S6A, S6D }\end{array}$ \\
\hline $\begin{array}{l}\angle R R C 8 C^{-/} \\
\text {(HCT116) }\end{array}$ & $\mathrm{n} 1 \mathrm{C}-\mathrm{C} 2$ & $1 \mathrm{C}$ & duplication of $\mathrm{t} 119$ & F41V-fs in TMD1 & $\begin{array}{l}\text { Fig. } 2 B, 2 C, 2 D \\
\text { fig. S6A, S6D }\end{array}$ \\
\hline \multirow[t]{2}{*}{$\begin{array}{l}\angle R R C 8 D^{-/} \\
\text {(HCT116) }\end{array}$} & n1D-F11 & $1 \mathrm{D}$ & $\begin{array}{l}\text { a1: } \Delta 19 n t(a 325-\mathrm{t} 343) \\
\text { a2: duplication of a325 }\end{array}$ & $\begin{array}{l}\text { D1: P110L-fs between TMD1 and TMD2 } \\
\text { D2: I109N-fs between TMD1 and TMD2 }\end{array}$ & \multirow{2}{*}{$\begin{array}{l}\text { Fig. 2B, 2D; fig. S6D } \\
\text { data from both clones } \\
\text { pooled for: Fig. 2C } \\
\text { fig. S6A }\end{array}$} \\
\hline & n1D-B2 & $1 \mathrm{D}$ & duplication of a325 & I109N-fs between TMD1 and TMD2 & \\
\hline \multirow{2}{*}{$\begin{array}{l}\mathrm{LRRC}^{\prime} E^{\prime-} \\
\text { (HCT116) }\end{array}$} & $\mathrm{BCDE}(\mathrm{WT})-\mathrm{F} 5$ & $1 \mathrm{E}$ & duplication of a94 & T32N-fs in TMD1 & \multirow{2}{*}{$\begin{array}{l}\text { Fig. 2B; fig. S6A } \\
\text { both clones: fig. S10B } \\
\text { data from both clones } \\
\text { pooled for: } \\
\text { Fig. 2C, 2D; fig. S6D }\end{array}$} \\
\hline & $\mathrm{CE}(\mathrm{WT})-\mathrm{B} 6$ & $1 \mathrm{E}$ & duplication of a94 & T32N-fs in TMD1 & \\
\hline \multirow{4}{*}{$\begin{array}{l}\text { LRRC8(D/E) } \\
\text { (HCT116) }\end{array}$} & \multirow{2}{*}{$\begin{array}{l}\text { nBCDE } \\
\text { (WT)-G9 }\end{array}$} & \multirow[t]{2}{*}{$1 \mathrm{D}, 1 \mathrm{E}$} & D: duplication of a325 & D: I109N-fs between TMD1 and TMD2 & \multirow{4}{*}{$\begin{array}{l}\text { Fig. 2B; fig. S6A } \\
\text { - data from both clones } \\
\text { pooled for: } \\
\text { Fig. 2C, 2D; fig. S6D }\end{array}$} \\
\hline & & & E: duplication of a94 & $\mathrm{E}: \mathrm{T32N-fs}$ in TMD1 & \\
\hline & \multirow{2}{*}{$\begin{array}{l}\text { nBCDE } \\
\text { (WT)-B3 }\end{array}$} & \multirow[t]{2}{*}{$1 \mathrm{D}, 1 \mathrm{E}$} & D: duplication of a325 & D: $1109 \mathrm{~N}$-fs between TMD1 and TMD2 & \\
\hline & & & E: duplication of a94 & $\mathrm{E}: \mathrm{T32N-fs}$ in TMD1 & \\
\hline \multirow[t]{2}{*}{$\begin{array}{l}\operatorname{LRRC8}(\mathrm{C} / \mathrm{E})^{-/ 2} \\
\text { (HCT116) }\end{array}$} & \multirow[t]{2}{*}{$\begin{array}{l}\text { BCDE(WT)- } \\
\text { F5+1C-D5 }\end{array}$} & \multirow[t]{2}{*}{$1 \mathrm{C}, 1 \mathrm{E}$} & $\begin{array}{ll}\mathrm{C}: & \text { a1: duplication of } \mathrm{t} 119 \\
& \text { a2: } \Delta 5 \mathrm{nt}(\mathrm{c} 114-\mathrm{g} 118) \text { and } \\
& \text { duplication of } \mathrm{t} 119 \\
\end{array}$ & $\begin{array}{l}\text { C1: F41V-fs in TMD1 } \\
\text { C2: G39C-fs in TMD1 }\end{array}$ & \multirow[t]{2}{*}{$\begin{array}{l}\text { Fig. 2B, 2C, 2D; } \\
\text { fig. S6A, S6D }\end{array}$} \\
\hline & & & E: duplication of a94 & $\mathrm{E}: \mathrm{T32N-fs}$ in TMD1 & \\
\hline \multirow[t]{3}{*}{$\begin{array}{l}\text { LRRC8 }(C / D / E)^{-/} \\
\text {(HCT116) }\end{array}$} & \multirow[t]{3}{*}{$n B C D E(W T)-H 8$} & \multirow[t]{3}{*}{$1 \mathrm{C}, 1 \mathrm{D}, 1 \mathrm{E}$} & $\begin{array}{l}\text { C: } 78 \text { nt (from a66 onwards) incl. } \\
\text { splice acceptor site replaced by } \\
13 \text { nt (net } \Delta 65 \mathrm{nt} \text { ) }\end{array}$ & $\begin{array}{l}\text { C: W23R-fs at start of TMD1, before } \\
\text { missing splice site }\end{array}$ & \multirow[t]{3}{*}{ Fig. 2B, 2C } \\
\hline & & & $\begin{array}{ll}\text { D: } & \text { a1: duplication of a325 } \\
& \text { a2: } \Delta 11 \mathrm{nt} \text { (g322-t332) } \\
\end{array}$ & $\begin{array}{l}\text { D1: I109N-fs between TMD1 and TMD2 } \\
\text { D2: D108Q-fs between TMD1 and TMD2 }\end{array}$ & \\
\hline & & & $\begin{array}{l}\text { E: a1: duplication of a94 } \\
\text { a2: } \Delta 10 \text { nt (g87-c96) }\end{array}$ & $\begin{array}{l}\text { E1: T32N-fs in TMD1 } \\
\text { E2: Y30W-fs in TMD1 }\end{array}$ & \\
\hline \multirow[t]{4}{*}{$\begin{array}{l}\operatorname{LRRC8}(B / C / D / E)^{/-} \\
\text {(HCT116) }\end{array}$} & \multirow[t]{4}{*}{$\begin{array}{l}\text { BCDE } \\
\text { (WT2)-D2+2B-E8 }\end{array}$} & \multirow[t]{4}{*}{$2 \mathrm{~B}, 1 \mathrm{C}, 1 \mathrm{D}, 1 \mathrm{E}$} & $\begin{array}{l}\text { B: a1: duplication of t446 } \\
\text { a2: } \Delta 2 \text { nt (c447-g448) }\end{array}$ & $\begin{array}{l}\text { B1: E150R-fs after TMD2 } \\
\text { B2: E150A-fs after TMD2 }\end{array}$ & \multirow[t]{4}{*}{ Fig. 2B, 2C; Fig. 4A } \\
\hline & & & C: duplication of t119 & C: F41V-fs in TMD1 & \\
\hline & & & D: duplication of a325 & D: I109N-fs between TMD1 and TMD2 & \\
\hline & & & $\mathrm{E}: \Delta 2 \mathrm{nt}$ (t92-c93) & $\mathrm{E}: \mathrm{L} 31 \mathrm{H}$-fs in TMD1 & \\
\hline \multirow{5}{*}{$\begin{array}{l}\mathrm{LRRCB}^{/-} \\
\text {(HCT116) }\end{array}$} & \multirow{5}{*}{$\begin{array}{l}\mathrm{BC}+\mathrm{DE} \\
\text { (KO)D5+ } \\
2 \mathrm{~B}-\mathrm{G} 4\end{array}$} & \multirow{5}{*}{$\begin{array}{l}3 \mathrm{~A}, 2 \mathrm{~B}, 1 \mathrm{~B}^{\S}, 1 \mathrm{C} \\
1 \mathrm{D}, 1 \mathrm{E}\end{array}$} & A: $\Delta 2 \mathrm{~g}$ out of $6 \mathrm{~g}(\mathrm{~g} 124-\mathrm{g} 129)$ & A: G43D-fs in TMD1 & \multirow{5}{*}{$\begin{array}{l}\text { Fig. 2E, 2F, 2G; } \\
\text { fig. S6B, S6C, S6E }\end{array}$} \\
\hline & & & $\begin{array}{l}\text { B: a1: duplication of t446 } \\
\text { a2: } \Delta 4 \mathrm{nt}(\mathrm{c} 447-\mathrm{g} 450)\end{array}$ & $\begin{array}{l}\text { B1: E150R-fs after TMD2 } \\
\text { B2: E150l-fs after TMD2 }\end{array}$ & \\
\hline & & & C: duplication of t119 & C: F41V-fs in TMD1 & \\
\hline & & & D: duplication of a325 & D: $1109 \mathrm{~N}$-fs between TMD1 and TMD2 & \\
\hline & & & $\mathrm{E}:$ duplication of a94 & $\mathrm{E}: \mathrm{T} 32 \mathrm{~N}$-fs in TMD1 & \\
\hline
\end{tabular}

$\mathrm{a}=$ allele (only given if alleles differed in modifications); $\mathrm{fs}=$ frameshift; $\mathrm{nt}=$ nucleotide; TMD = transmembrane domain; ZFN = zinc-finger nuclease; $\Delta=$ deletion Indicated nucleotide numbers give nucleotide position within the ORF.

${ }^{*}$ For targeted guide sequences, see table S4.

${ }^{\S}$ Targeting with construct $1 \mathrm{~B}$ in $L R R C 8^{/-}$cell line resulted in a duplication of a1043 which would lead to A349G-fs after TMD4. However, the mutations by the $2 \mathrm{~B}$ targeting (given in table) truncate LRRC8B already after TMD2. 
Table S4. Guide sequences used for the generation of knock-out cell lines with the CRISPR/Cas system.

\begin{tabular}{|c|c|c|c|c|}
\hline Target gene & Construct & Guide sequence $\left(5^{\prime} \rightarrow 3^{\prime}\right)$ & Targeting strand & Target location in protein \\
\hline$\angle R R C 8 A$ & $\begin{array}{l}1 \mathrm{~A} \\
3 \mathrm{~A} \\
4 \mathrm{~A}\end{array}$ & $\begin{array}{l}\text { ggctgatgtagaaggacgccagg } \\
\text { tgatgattgccgtcttcgggggg } \\
\text { tcctgcaatgattcgttccgggg }\end{array}$ & $\begin{array}{l}- \\
+ \\
+\end{array}$ & $\begin{array}{l}\text { aa 320-328 (beginning of TMD4) } \\
\text { aa 36-43 (in TMD2) } \\
\text { aa 64-71 (between TMD1 and TMD2) }\end{array}$ \\
\hline$L R R C 8 B$ & $\begin{array}{l}1 \mathrm{~B} \\
2 \mathrm{~B}\end{array}$ & $\begin{array}{l}\text { ttttctcttaacgcctcaaagg } \\
\text { ggccacaaaatgctcgagectgg }\end{array}$ & - & $\begin{array}{l}\text { aa 346-353 (after TMD4) } \\
\text { aa 147-354 (between TMD2 and TMD3) }\end{array}$ \\
\hline$\angle R R C 8 C$ & $1 \mathrm{C}$ & atgctcatgatcggcgtgtttgg & + & aa 35-42 (in TMD1) \\
\hline$\angle R R C 8 D$ & $1 \mathrm{D}$ & gtggctctgagaggtatgtcagg & - & aa 107-114 (between TMD1 and TMD2) \\
\hline LRRC8E & $1 \mathrm{E}$ & gctggccgagtacctcaccgtgg & + & aa 27-34 (inTMD1) \\
\hline
\end{tabular}

aa= amino acid; TMD = transmembrane domain; PAM sequences are underlined

\section{Supplementary References}

33. T. J. Lopes et al., Bioinformatics 27, 2414 (2011).

34. A. Krogh, B. Larsson, G. von Heijne, E. L. Sonnhammer, J Mol Biol 305, 567 (2001).

35. P. Mali et al., Science 339, 823 (2013).

36. M. B. Rust et al., J Clin Invest 117, 1708 (2007).

37. S. Arvidsson, M. Kwasniewski, D. M. Riano-Pachon, B. Mueller-Roeber, BMC Bioinformatics 9, 465 (2008).

38. J. E. Capó-Aponte, P. Iserovich, P. S. Reinach, J Membr Biol 207, 11 (2005). 